\title{
BMP9 counteracts the tumorigenic and pro-angiogenic potential of glioblastoma
}

\author{
Elena Porcù ${ }^{1}$ - Francesca Maule ${ }^{1}$ Daniele Boso ${ }^{1}$ Elena Rampazzo ${ }^{1}$ - Vito Barbieri ${ }^{2,3}$ - Gaia Zuccolotto ${ }^{2}$. \\ Antonio Rosato ${ }^{2,3} \cdot$ Chiara Frasson $^{1,4} \cdot$ Giampietro Viola $^{1}$ - Alessandro Della Puppa ${ }^{5}$ - Giuseppe Basso ${ }^{1}$. \\ Luca Persano $\mathbb{B D}^{4}$
}

Received: 19 October 2017 / Revised: 21 May 2018 / Accepted: 6 June 2018 / Published online: 5 July 2018

(c) ADMC Associazione Differenziamento e Morte Cellulare 2018

\begin{abstract}
Glioblastoma multiforme (GBM) is a highly vascularized and aggressive brain tumor, with a strong ability to disseminate and invade the surrounding parenchyma. In addition, a subpopulation of GBM stem cells has been reported to possess the ability to transdifferentiate into tumor-derived endothelial cells (TDECs), supporting the resistance to anti-angiogenic treatments of newly formed blood vessels. Bone Morphogenetic Protein 9 (BMP9) is critically involved in the processes of cancer cell differentiation, invasion and metastasis, representing a potential tool in order to impair the intrinsic GBM aggressiveness. Here we demonstrate that BMP9 is able to trigger the activation of SMADs in patient-derived GBM cells, and to strongly inhibit proliferation and invasion by reducing the activation of PI3K/AKT/MAPK and RhoA/Cofilin pathways, respectively. Intriguingly, BMP9 treatment is sufficient to induce a strong differentiation of GBM stem-like cells and to significantly counteract the already reported process of GBM cell transdifferentiation into TDECs not only in in vitro mimicked TDEC models, but also in vivo in orthotopic xenografts in mice. Additionally, we describe a strong BMP9mediated inhibition of the whole angiogenic process engaged during GBM tumor formation. Based on these results, we believe that BMP9, by acting at multiple levels against GBM cell aggressiveness, can be considered a promising candidate, to be further developed, for the future therapeutic management of GBM.
\end{abstract}

Edited by RA Knight

These authors contributed equally: Giuseppe Basso, Luca Persano.

Electronic supplementary material The online version of this article (https://doi.org/10.1038/s41418-018-0149-9) contains supplementary material, which is available to authorized users.

Luca Persano

luca.persano@unipd.it

1 Department of Woman and Children Health, University of Padova, Padova, Italy

2 Department of Surgery, Oncology and Gastroenterology, University of Padova, Padova, Italy

3 Istituto Oncologico Veneto IOV-IRCCS, Padova, Italy

4 Istituto di Ricerca Pediatrica - Città della Speranza - IRP, Padova, Italy

5 Neurosurgery Unit, Padova University Hospital, Padova, Italy

\section{Introduction}

Glioblastoma multiforme (GBM) represents the most malignant brain tumor characterized by a very poor prognosis despite intensification of therapy regimens [1]. Indeed, GBM are heavily aggressive tumors, due to their marked invasive properties and the presence of highly heterogenic cell phenotypes. In particular, a subpopulation of cells endowed with stem-like characteristics (GSCs) have been reported to be resistant to chemotherapeutics [2, 3]. In this context, an increasing number of studies suggest prodifferentiating agents as emerging GBM therapeutic tools [4-6].

GBM is characterized by a peculiar hypoxic microenvironment that plays a key role in the maintenance of GBM stemness [7] and provides a potent pro-angiogenic stimulus [8]. Intriguingly, GSCs have been recently described to be able to support GBM neovascularization by transdifferentiating into tumor-derived endothelial cells (TDECs) [9], characterized by the expression of multiple endothelial markers such as CD34, VE-cadherin, CD31 and 
A

\begin{tabular}{|c|c|c|}
\hline \multirow{2}{*}{$\frac{\text { CTR }}{\mathrm{oh}}$} & BMP9 & \multirow{3}{*}{ p-Smad1/5/8 } \\
\hline & $6 h$ & \\
\hline & & \\
\hline & & Smad1/5/8 \\
\hline & & p-Smad2 \\
\hline & & Smad2 \\
\hline & & $\beta$-actin \\
\hline
\end{tabular}

B

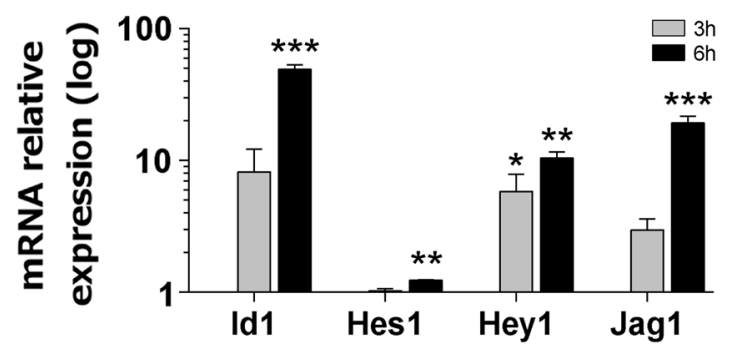

(HuTuP108/175). Data are presented as mean \pm S.E.M of $N=3$ independent experiments (b). ${ }^{*} p<0.05$; ${ }^{*} p<0.01 ; * * * p<0.001$ by paired $t$-test primary cells. Immunoblotting of indicated proteins following 3-6 h of BMP9 treatment at $30 \mathrm{ng} / \mathrm{ml}$ (HuTuP175). a Relative mRNA expression of SMADs target genes relative to untreated cells $(0 \mathrm{~h})$

von Willebrand Factor (vWF) [10]. Since TDECs have been reported to lack the expression of VEGF receptors, thus being resistant to classical anti-angiogenic therapies $[10,11]$, the inhibition of this transdifferentiation process would potentially overcome anti-angiogenic therapy resistance in GBM [12].

BMPs are members of the TGF- $\beta$ family of ligands involved in tissue development and cell type specification $[13,14]$. BMPs have been described to induce differentiation and inhibit proliferation and invasiveness in various cancers [15-18] including GBM [5, 19-24]. In addition, they were identified as molecular regulators of angiogenesis and vascular development [25], with BMP9 mutations being the major cause of some vascular syndromes [26]. Indeed, the BMP9 receptor Activin receptor-Like Kinase 1 (ALK1) is specifically expressed in endothelial cells (EC) $[27,28]$. Given these reported effects of BMP9 on both tumor and EC [16, 17, 27-29], it may be exploited as an effective anti-cancer agent in GBM.

Here, we analyzed the effects exerted by BMP9 treatment on both GSCs and GSC-derived EC (i.e., TDECs). In particular, our results support the anticipated prodifferentiating effects of BMP9 in GBM cells, and demonstrate its peculiar ability of antagonizing TDECs formation in vitro. Moreover, the process of cell lineage specification is strictly dependent on tissue microenvironment, with hypoxia and HIF- $1 \alpha$ activation being a hallmark of GBM tumors in order to sustain their undifferentiated phenotype and trigger a pro-angiogenic stimuli [7, 30, 31]. To support our results, we analyzed BMP9 treatment effects also in vivo in orthotopic xenograft GBM models in mice, showing that BMP9 may act in vivo as a dual anti-cancer agent by directly counteracting tumor growth through induction of GBM cell differentiation and the impairment of tumor angiogenesis and TDECs formation.

\section{Results}

\section{BMP9 activates SMAD1/5/8 and SMAD2-dependent transcription in GBM cells}

BMP9 has been described as a regulator of cell proliferation, self-renewal and differentiation. In particular, with the contribution of the co-receptor Endoglin, BMP9 binds both ALK1 and ALK5 receptors, and activates the canonical pathway effectors SMAD1/5/8 and SMAD2/3, respectively [32]. As a first step, we evaluated the ability of BMP9 to activate its intracellular downstream cascade in GBM cells, showing a rapid phosphorylation of both SMAD2 and SMAD1/5/8 after treatment (Fig. 1a). As a confirmation of canonical signaling activation, the transcription of the SMADs direct target Id1 (IDI gene) [28, 29, 32], together with the Notch-dependent SMAD-controlled genes Hes1, Hey1 and Jag1 (HES1, HEYl, JAG1 genes) [33], were significantly up-regulated following SMAD phosphorylation (Fig. 1b). As a positive control, a concurrent upregulation of Endoglin (ENG gene) was observed (Suppl. Fig. S1), confirming the engagement of a described liganddependent pro-stimulatory loop of the signaling [28]. These data suggest that BMP9 is able to efficiently activate both canonical ALK1 and ALK5-dependent intracellular signaling in GBM cells.

\section{BMP9 impairs cell proliferation, migration and invasion in vitro}

The effects of BMP9 in GBM cells have never been reported so far. Here, we show that a 10 day treatment with BMP9 (30 ng/ml any other day) was sufficient to strongly inhibit GBM cell proliferation, without affecting cell viability (Fig. 2a, b and Suppl. Fig. S2A). Moreover, Ki67 immunofluorescence confirmed a significant decrease of 

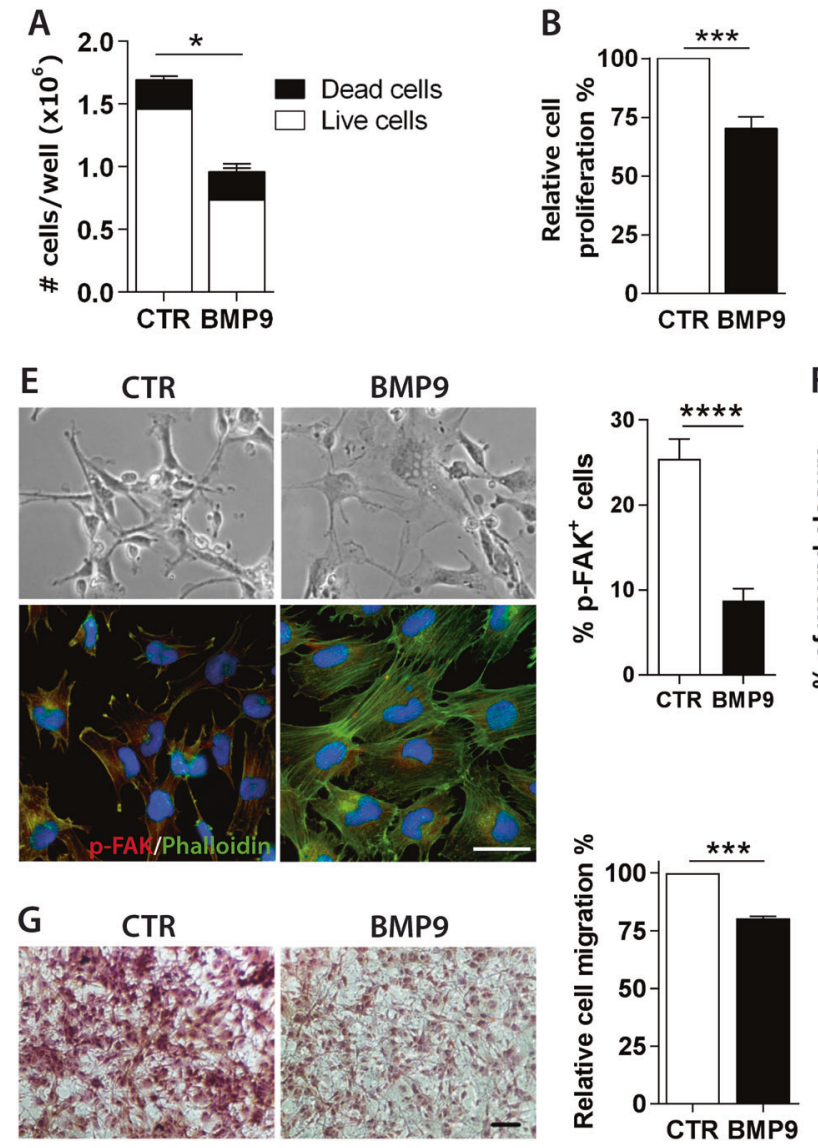

Fig. 2 BMP9 effects on GBM invasiveness in vitro. Trypan blue count after BMP9 treatment at $30 \mathrm{ng} / \mathrm{ml}$ every other day for 10 days (HuTuP82/83/187) (a). Cell proliferation evaluated by MTT assay, after further $72 \mathrm{~h}$ of BMP9 treatment at $30 \mathrm{ng} / \mathrm{ml}$ added to previous 10 day exposure (HuTuP82/83) (b). Quantification of the percentage of $\mathrm{Ki}_{6} 7^{+}$cells treated with BMP9 $30 \mathrm{ng} / \mathrm{ml}$ every other day for 10 days (HuTuP83/108) (c). Immunoblotting of indicated proteins following $24 \mathrm{~h}$ of BMP9 treatment at $30 \mathrm{ng} / \mathrm{ml}$ (HuTuP13/108) (d). Representative images of HuTuP13 cells treated with BMP9 $30 \mathrm{ng} / \mathrm{ml}$ every other day for 10 days, captured by optical microscope (original magnification $10 \times$, scale $b a r=100 \mu \mathrm{m}$, upper panel) and marked with phalloidin-FITC (green) and p-FAK antibody (red). Cell nuclei have been counterstained with DAPI (blue) (original magnification 20x, scale $b a r=50 \mu \mathrm{m}$, lower panel). Relative quantification of $\mathrm{p}-\mathrm{FAK}^{+}$

GBM growth after treatment (Fig. 2c and Suppl. Fig. S2B). In order to deepen the molecular events underlying these effects, we analyzed the activation status of multiple intracellular effectors involved in the regulation of cell survival and proliferation, demonstrating a BMP9-mediated deactivation of PI3K, AKT and ERK1/2 as previously suggested $[17,34,35]$, finally resulting in the up-regulation of the cell cycle inhibitors p21 and p27 (Fig. 2d). Intriguingly, BMP9 treatment even induced $\mathrm{p} 38$ phosphorylation, suggesting the potential activation of a non-classical p38-dependent activation of p21 (Fig. 2d) [36].

Given the well-known role of BMP9 in reducing cell migration and invasion of breast cancer cells [16, 37], we

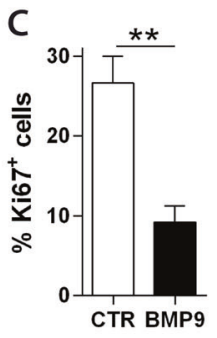

$\mathbf{F}$
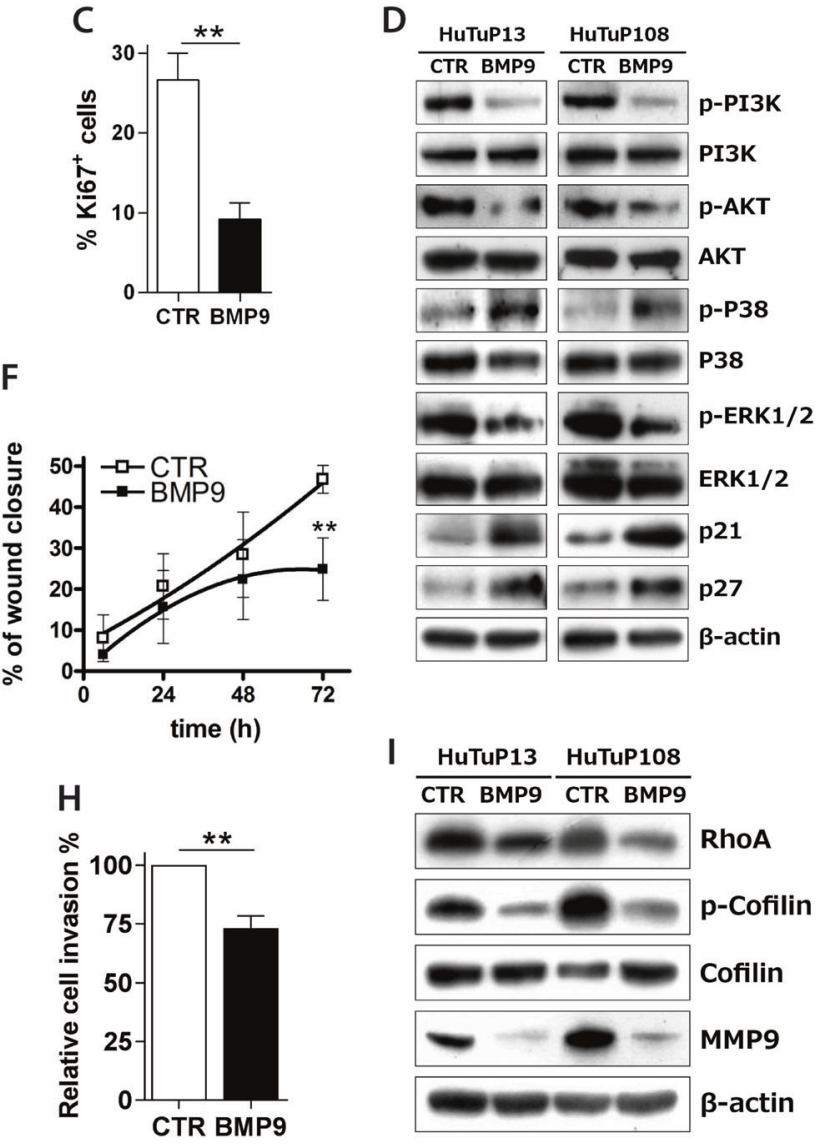

cells (right graph) (e). Quantification of wound closure of control or BMP9-treated $30 \mathrm{ng} / \mathrm{ml}$ during time (HuTuP10/83). Statistical significance by paired t-test at $72 \mathrm{~h}$ (f). Transwell migration assay of GBM primary cells (HuTuP83/13/82/175) treated with BMP9 $30 \mathrm{ng} /$ $\mathrm{mL}$ for $24 \mathrm{~h}$, and stained with Crystal violet. Representative images (original magnification $10 \times$, scale bar $=100 \mu \mathrm{m}$, left) and relative quantification of the absorbance at $560 \mathrm{~nm}$ of solubilized Crystal Violet (right) (g). Percentage of cell invasion (HuTuP10/13) measured by the Cultrex transwell assay, after $48 \mathrm{~h}$ of treatment (h). Immunoblotting of indicated proteins following 10 days of BMP9 treatment at $30 \mathrm{ng} / \mathrm{ml}$ (HuTuP13/108) (i). Data are presented as mean \pm S.E.M. of $N \geq 3$ independent experiments. ${ }^{*} p<0.05 ;{ }^{*} p<0.01$; $* * * p<0.001$; $* * * * \mathrm{p}<0.0001$ by $t$-test

analyzed these potential effects also in GBM. BMP9 induced a strong rearrangement of intracellular actin filaments together with the disappearance of phosphorylated FAK from focal adhesions of cells (Fig. 2e), resulting in a significant reduction of GBM cell motility by the scratch test (Fig. 2f and Suppl. Fig. S3A) [38, 39]. As a further confirmation, we observed a strong impairment of GBM cell migration across transwell inserts upon BMP9 treatment (Fig. 2g). In addition, we assessed the invasive properties of GBM cells, demonstrating that BMP9 significantly decreased the proportion of cells invading or passing through basal membrane extract-coated transwells (Fig. 2h). Accordingly, BMP9 potently decreased 
the intracellular levels of RhoA and phospho-Cofilin pro-migratory factors (Fig. 2i), and induced a clear-cut inhibition of the pro-invasion enzyme MMP9 [40] (Fig. 2i and Suppl. Fig. S3B), thus molecularly sustaining our results.

\section{BMP9 inhibits self-renewal of GSCs and promotes their differentiation}

Given the anticipated role of BMPs in regulating GBM cell phenotype $[5,19,20,22]$, we analyzed the potential prodifferentiating effects exerted by BMP9 on GSCs. Selfrenewing properties of GSCs were dramatically impaired by BMP9 as demonstrated by a clear-cut reduction of both the size (Fig. 3a) and the number (Fig. 3b) of the GBM neurospheres generated in non-adhesive conditions. Interestingly, BMP9 was even able to induce spheres to attach to the bottom of culturing wells (Suppl. Fig. S4A). In addition, BMP9-treated cells were subjected to a significant reduction of their GSC frequency (Fig. 3c), suggesting that GBM cell differentiation occurs upon BMP9 stimulation. In this context, BMP9 treated cells acquired a more flattened and astrocytic-like shape (Fig. 3d). Importantly, these morphological rearrangements were associated with a concomitant decrease in the expression of the neural stem cell (NSC) markers Nanog, Sox2 and Olig2 (NANOG, SOX2, OLIG2 genes) [19], and a significant over-expression of the differentiation markers GFAP and $\beta$ III-tubulin (GFAP and TUBB3 3 genes) (Fig. 3e). We further confirmed these data by flow cytometry, which showed that BMP9-treated GBM cells reduced the expression of CD133, Sox 2 and Nestin, indicative of undifferentiated cells, and CD24, indicative of mature neurons, in favor of the astrocytic marker CD44 [41] (Fig. 3f-g). Along this line, immunofluorescence analysis disclosed a significant BMP9-mediated reduction of Nestin and Nanog, and a dramatic increase of the proportion of S100 and/or $\beta$ III-tubulin expressing cells (Fig. 3h, i).

Differentiation of NSCs into $\mathrm{GFAP}^{+}$astrocytes in the normal brain is preceded by a stepwise series of progenitor cell (i.e., radial glia) divisions characterized by a peculiar phosphorylation of vimentin $\left(\mathrm{p}-\mathrm{Vim}^{+}\right)$. These progenitors then progressively lose their multi-lineage ability and finally acquire a more differentiated astrocytic $\left(\mathrm{GFAP}^{+}\right)$phenotype (Suppl. Fig. S4B) [42]. BMP9 treatment of GBM cells induced a significant stimulation of GBM "progenitor-like" cell symmetric divisions $\left(\mathrm{p}-\mathrm{Vim}^{+}\right.$cell doublets) and a concomitant increase of their astrocytic differentiation ( $\mathrm{p}$ $\mathrm{Vim}^{+} / \mathrm{GFAP}^{+}$and $\mathrm{pVim}^{-} / \mathrm{GFAP}^{+}$) (Fig. 3j and Suppl. Fig. S4C). In addition, BMP9 limited the mean expression of CD56, described to be harbored by GBM neurospheres, but not by serum supplemented (more differentiated) cells (Suppl. Fig. S4D) [43].

\section{BMP9 counteracts GSC transdifferentiation into TDECs}

The ability of GSC to actively participate in tumor angiogenesis has already been reported in GBM demonstrating that most immature GBM cells are able to transdifferentiate into ECs in particular microenvironmental conditions $[10,44]$. In order to model in vitro this process, we cultured primary GBM cells in EC medium, which was sufficient to induce a strong remodeling of GBM cell morphology by itself. Indeed, cells acquired a more flattened phenotype when compared to GBM medium, in which cells maintained a cluster growth and formed neurosphere-like structures (Fig. 4a). Importantly, EC medium-cultured GBM cells underwent a peculiar phenotypic switch by acquiring surface expression of endothelial progenitor markers such as CD34, VE-cadherin, and CD31 (Fig. 4b-d, white bars) and slightly reducing the percentage of $\mathrm{CD}_{133^{+}}$cells (Fig. S5A, white bars). These phenotypic changes were confirmed by the analysis of CD31 and VEcadherin transcripts and were accompanied by a significant over-expression of $\mathrm{vWF}, \mathrm{VEGF}$ and the proliferating EC marker Endoglin (PECAM1, CDH5, VWF, VEGFA and ENG genes respectively) mRNA (Fig. S5B, C, white bars). To further confirm also in our experimental setting that GBM TDECs basically derive from GSC differentiation $[9,10,45]$, we performed lineage tracing experiments in which FACS sorted GSCs $\left(\mathrm{CD} 133^{+}\right)$were stained by the cell membrane tracer CMDiI and then re-mixed 1:1 with unstained $\mathrm{CD} 133^{-}$cells to recreate tumor heterogeneity (Suppl. Fig. S5D). CMDiI tracking confirmed that our in vitro modeled TDECs mainly originate from GSCs as shown by their almost unique ability to acquire VEcadherin and CD31 surface expression (Suppl. Fig. S5E). In this context, BMP9 was able to consistently antagonize the process of TDEC formation by strongly impacting on TDEC shape and phenotype (Fig. 4a). BMP9 treatment significantly reduced the amount of $\mathrm{CD} 34^{+}$cells induced by EC medium (Fig. 4b) and concomitantly decreased the expression of both stem cell and EC markers (Fig. 4c, d and Suppl. Fig. S5A, B, E). Ricci-Vitiani et al. previously reported the existence of GBM-derived ECs aberrantly expressing GFAP [9]. In our experimental conditions, in vitro generated TDECs not only retained, but even increased GFAP expression, with BMP9 being able to significantly counteract this phenomenon (Fig. $4 \mathrm{e}$ and Suppl. Fig. S5B).

Given the well known ability of BMP9 to provide a potent osteogenic signal during bone formation and remodeling [29], we tested the possibility that a BMP9 treatmentdependent osteogenic differentiation would occur in our experimental conditions, and thus excluded any potential 
A

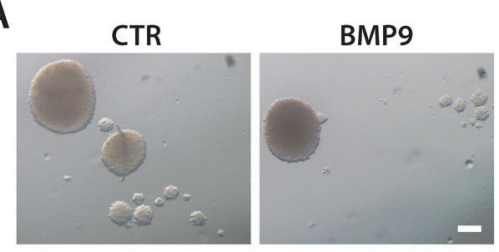

D
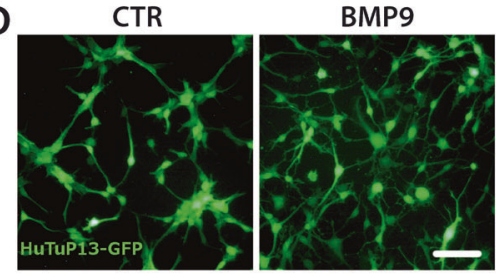

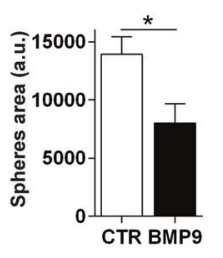

B

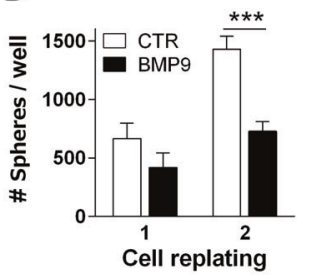

C

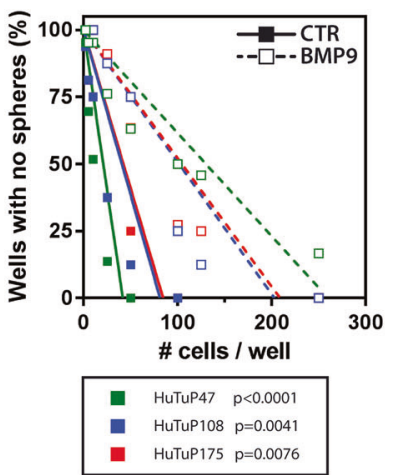

$\mathbf{F}$

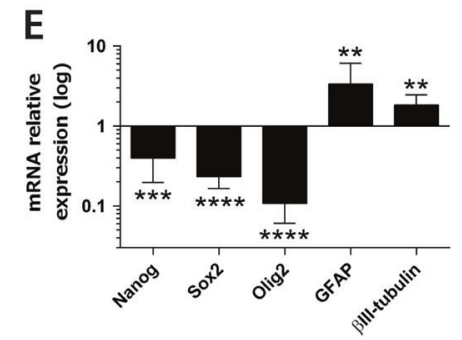

$\mathrm{H}$
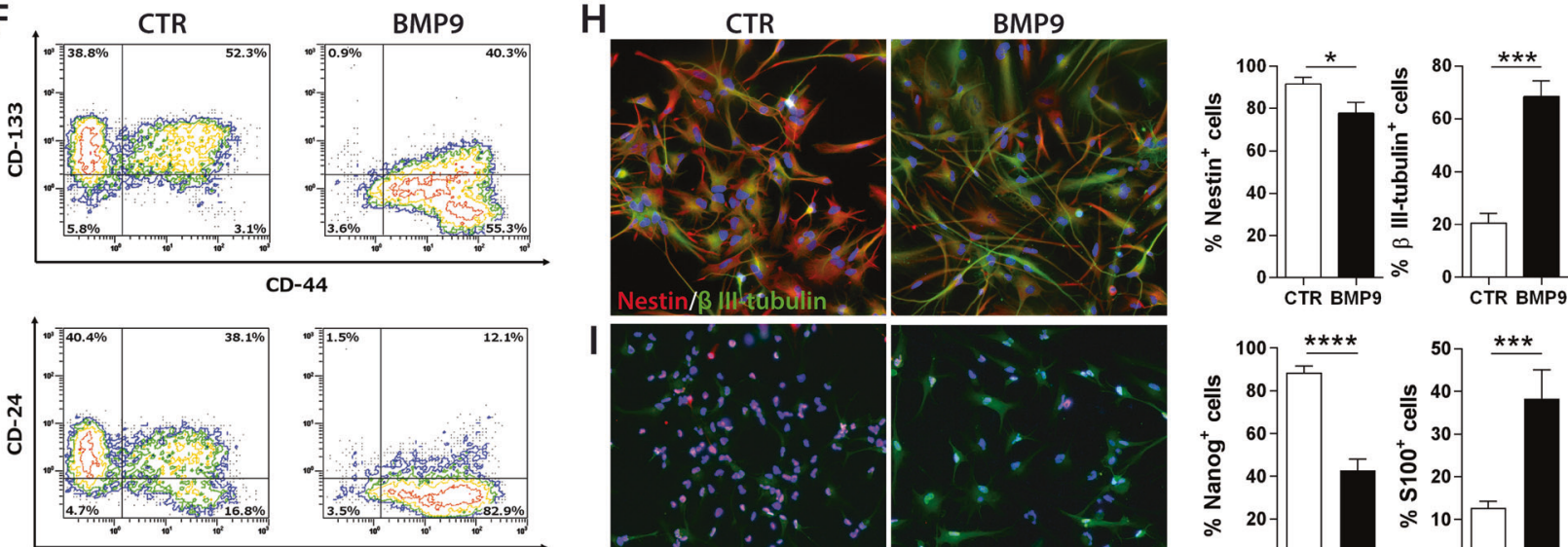

CD-44
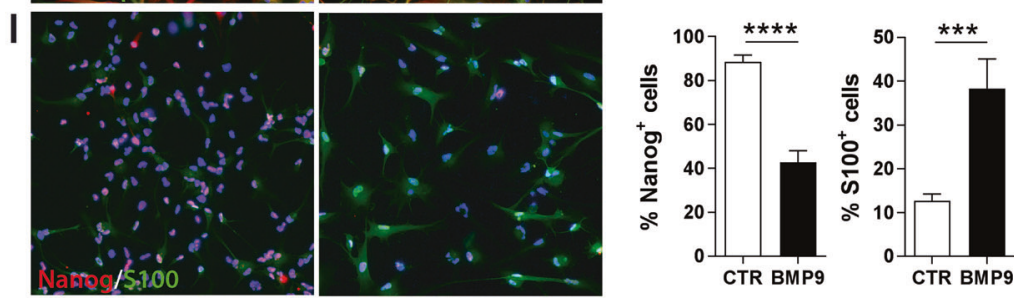

G
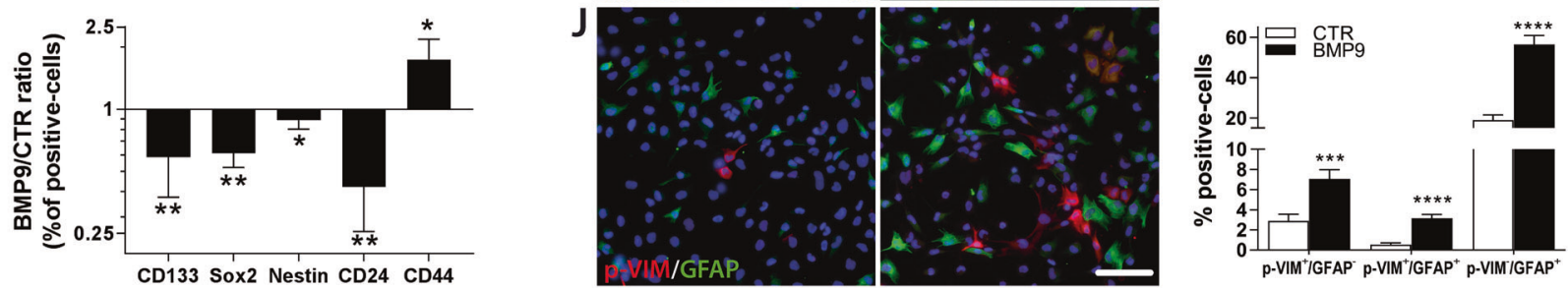

Fig. 3 Effects of BMP9 on GBM cell stemness and differentiation. Representative images of neurospheres formed by GBM cells plated as single cells after BMP9 $30 \mathrm{ng} / \mathrm{ml}$ pre-treatment every other day and controls, (original magnification $4 \times$, scale bar $=20 \mu \mathrm{m}$, left), and relative measurement of sphere areas $(\mathrm{HuTuP} 82 / 83 / 174$, right; a.u. $=$ arbitrary units) (a). Quantification of the number of spheres generated after the first and the second re-plating of control and treated GBM cells (HuTuP83/187) (b). Limiting dilution analysis of the frequency of control (solid lines) and BMP9-treated (dotted lines) GBM cells able to generate neurospheres (HuTuP47: $f=1 / 24$ versus $f=1 / 163$ in control and BMP9 treated cells, respectively; HuTuP108: $f=1 / 47$ versus $f=1 / 122$; HuTuP175: $f=1 / 49$ versus $f=1 / 123$ ) (c). Changes in cell morphology induced by BMP9 treatment for 10 days are highlighted by representative images of GFP-transduced cells (HuTuP13) (original magnification 10×, scale bar $=100 \mu \mathrm{m}$ ) (d). Relative mRNA expression of stem cell and differentiation

markers after 10 days of BMP9 treatment at $30 \mathrm{ng} / \mathrm{ml}$ every other day, respect to control cells (HuTuP10/13/82/83/175) (e). Representative contour plots of GBM cells treated with BMP9 at $30 \mathrm{ng} / \mathrm{ml}$ every other day for 10 days and analyzed by flow cytometry (HuTuP47) (f). Percentage of $\mathrm{CD} 133^{+}$, Sox $2^{+}, \mathrm{Nestin}^{+}, \mathrm{CD} 24^{+}$or $\mathrm{CD} 44^{+}$cell subpopulations detected after 10 days of treatment at $30 \mathrm{ng} / \mathrm{ml}$ every other day and expressed as the ratio between BMP9-treated and control samples (HuTuP10/47/82/83/174) (g). Representative immunofluorescence staining of GBM cells for Nestin/ $\beta$ III-tubulin (red and green respectively, h), Nanog/S100 (red and green respectively, i), pVIM/GFAP (red and green respectively, $\mathbf{j}$ ), and relative quantifications (right panels), after 10 days of BMP9 treatment at $30 \mathrm{ng} / \mathrm{ml}$ every other day (original magnification $20 \times$, scale bar $=50 \mu \mathrm{m})(\mathrm{HuTuP} 13 / 47 / 83 /$ 108/174). Cell nuclei have been counterstained with DAPI (blue). Data are presented as mean \pm S.E.M. of $N \geq 3$ independent experiments. $* p<0.05 ; * * p<0.01 ; * * * p<0.001 ; * * * * p<0.0001$, by paired $t$-test 

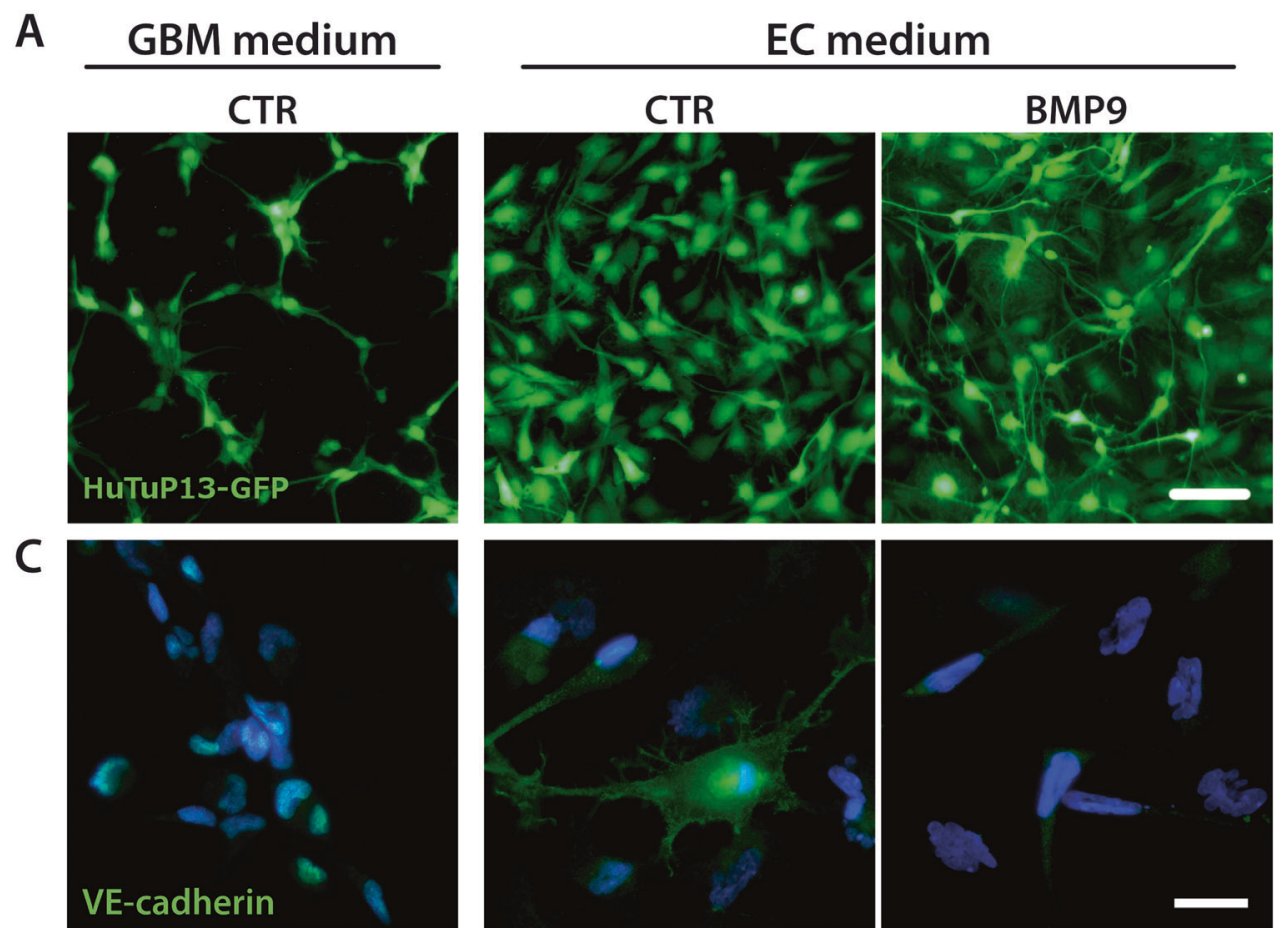

B
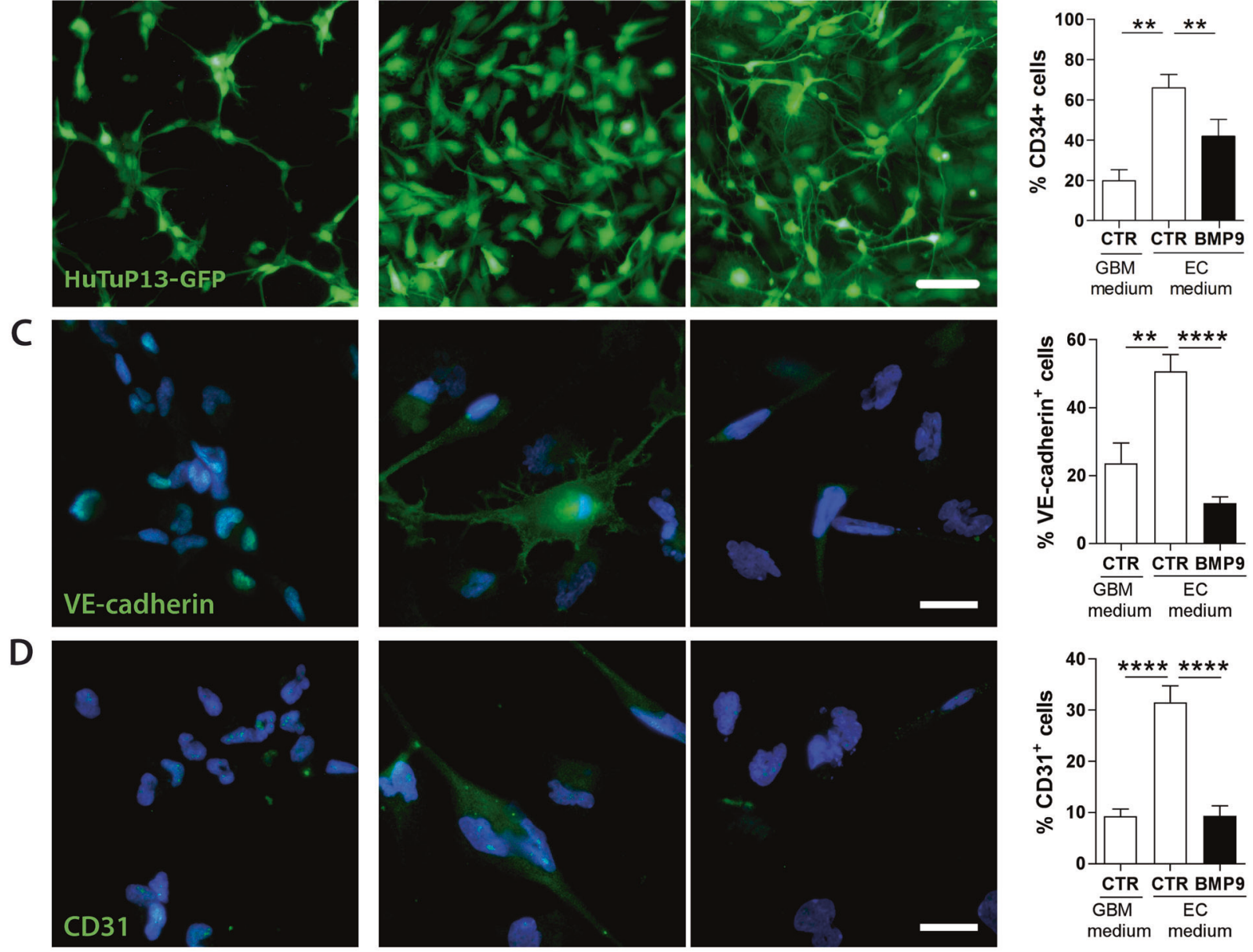

E
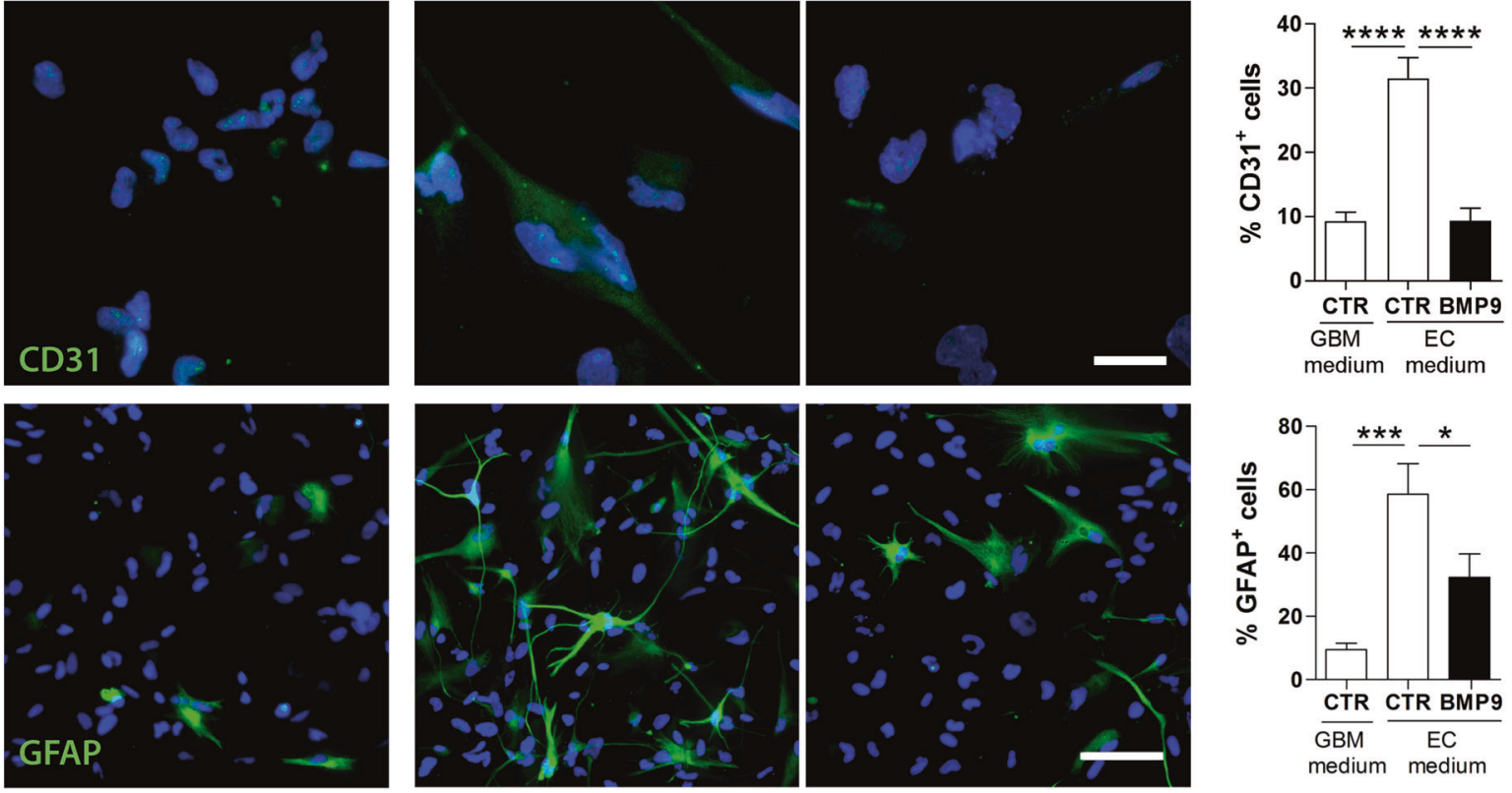

Fig. 4 Endothelial commitment is impaired by BMP9. Representative images showing cell morphology of GFP-transduced cells (HuTuP13) affected by EC medium and BMP9 treatment at $30 \mathrm{ng} / \mathrm{ml}$ every other day for 10 days (original magnification $10 \times$, scale bar $=100 \mu \mathrm{m}$ ) (a). Flow cytometry analysis of $\mathrm{CD} 34^{+}$after 10 days of treatment with BMP9 at $30 \mathrm{ng} / \mathrm{ml}$ every other day (HuTuP13/83/108/175) (b). Representative images (HuTuP174) of immunofluorescence

staining for VE-cadherin (green, c), CD31 (green, d), GFAP (green, e) and relative quantifications (right panels), after 10 days of treatment at $30 \mathrm{ng} / \mathrm{ml}$ every other day (original magnification $20 \times$, scale bar $=$ $50 \mu \mathrm{m})$. Data are presented as mean \pm S.E.M. of $N \geq 3$ independent experiments. $* p<0.05 ; * * p<0.01 ; * * * p<0.001 ; * * * * p<0.001$ by paired $t$-test or One-way ANOVA

induction of osteogenesis in both GBM end EC media (Suppl. Fig. S6).

Our results further confirm the peculiar ability of GSCs to transdifferentiate into EC in vitro and suggest BMP9 as a potent inhibitor of this process.

\section{BMP9 impairs TDEC migration and their self- assembly into vascular-like structures}

Endothelial cell migration represents an important process during physiological and pathological angiogenesis [31]. 
A
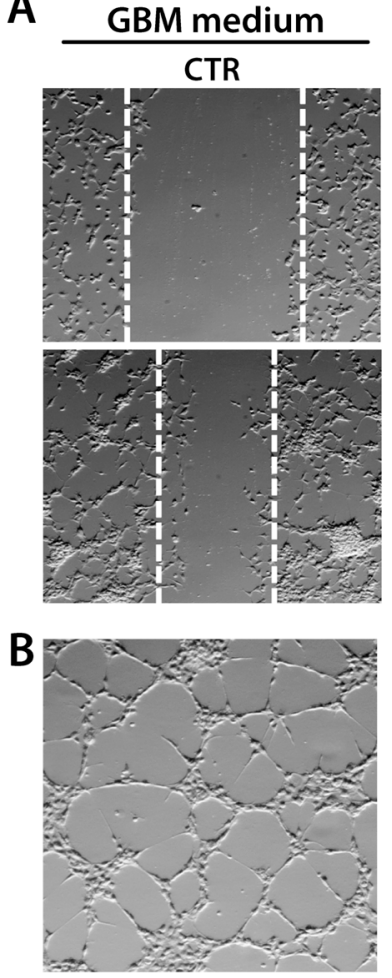

Fig. 5 BMP9 affects endothelial properties of GBM-TDECs. Representative images of wound assay $(7 \times$ magnification, scale bar $=$ $150 \mu \mathrm{m}$, left) and relative quantification (HuTuP10/83, right) of BMPtreated $(30 \mathrm{ng} / \mathrm{ml})$ EC-transdifferentiated GBM cells (a). Representative images (7x magnification, scale bar $=150 \mu \mathrm{m}$, left) and relative quantification of the number of meshes and branches (right panels) of

For this reason, we monitored the ability of in vitro generated TDECs to efficiently migrate and organize in vascular-like structures during EC commitment, and evaluated if BMP9 treatment could affect these features. TDECs showed a significant enhancement of their migratory properties relative to GBM medium-cultured cells, with BMP9 limiting cell motility also in this experiments (Fig. 5a). On the contrary, the ability of cells to organize in capillary-like structures was only slightly strengthened during endothelial commitment of cells (Fig. 5b). Nevertheless, BMP9 treatment significantly reduced the complexity of the modeled vascular network by significantly diminishing the number of meshes and branches generated during tubule formation (Fig. 5b). As a further support of this effect, BMP9 decreased the number of both vascular intersections (nodes) and isolated segments (Suppl. Fig. S7).

Importantly, although endothelial commitment was accompanied by a dramatic decline of cell proliferation, the above described BMP9 effects on TDECs motility/self organization were definitely independent from any potential BMP9-mediated anti-proliferative/toxic effect at the same time-points and dosages (Suppl. Fig. S8).

\section{BMP9 impairs GBM growth in vivo by reducing cell stemness and tumor angiogenesis}

Since GBM features are finely regulated by its peculiar microenvironment, we analyzed the effects of BMP9 also in vivo, in orthotopic GBM xenografts in mice. To this purpose, we stereotaxically injected control or BMP9 pretreated primary GBM cells (GFP-LUC-transduced) into NOD-SCID mice brains or either treated established GBM xenografts with two dosages of BMP9 $(1 \mu \mathrm{g}$ or $3 \mu \mathrm{g} /$ 14days) by intracranial osmotic pump infusion (Suppl. Fig. S9A). Vital bioluminescence tracking during timedisclosed a progressive and strong BMP9-mediated inhibition of GBM growth by both treatment schedules (Fig. 6a, b and Suppl. Fig. S9B). Histological analyses confirmed that control GBM cells gave rise to large tumors conversely to BMP9 pre-treated cells, which involved only a limited area of mice brains (Fig. 6c) or BMP9infused mice which showed a significant confinement of tumors and even the induction of intra-tumoral necrosis (Fig. 6d). Importantly, BMP9 treatment was sufficient to significantly impair the ability of GBM cells to invade tumor-surrounding normal brain tissues (Fig. 6e, f). 
A

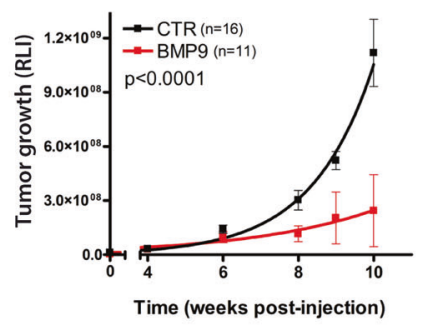

C
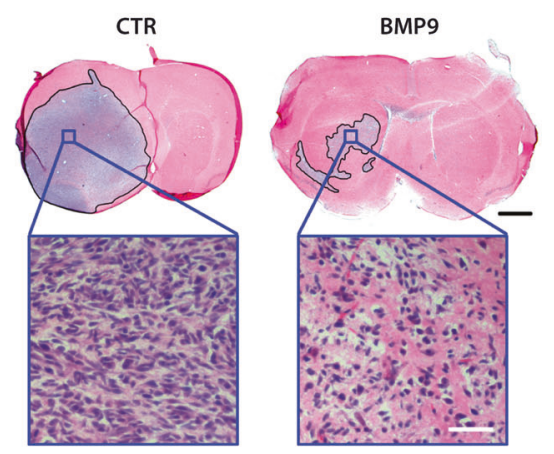

B

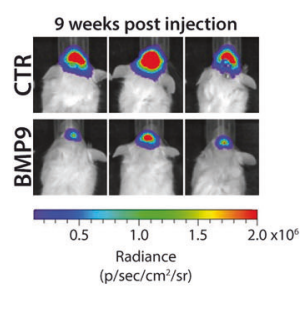

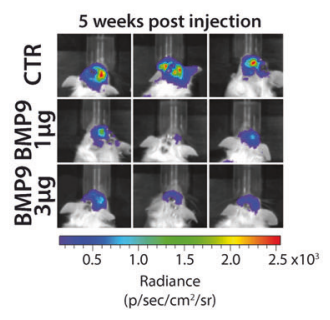

D
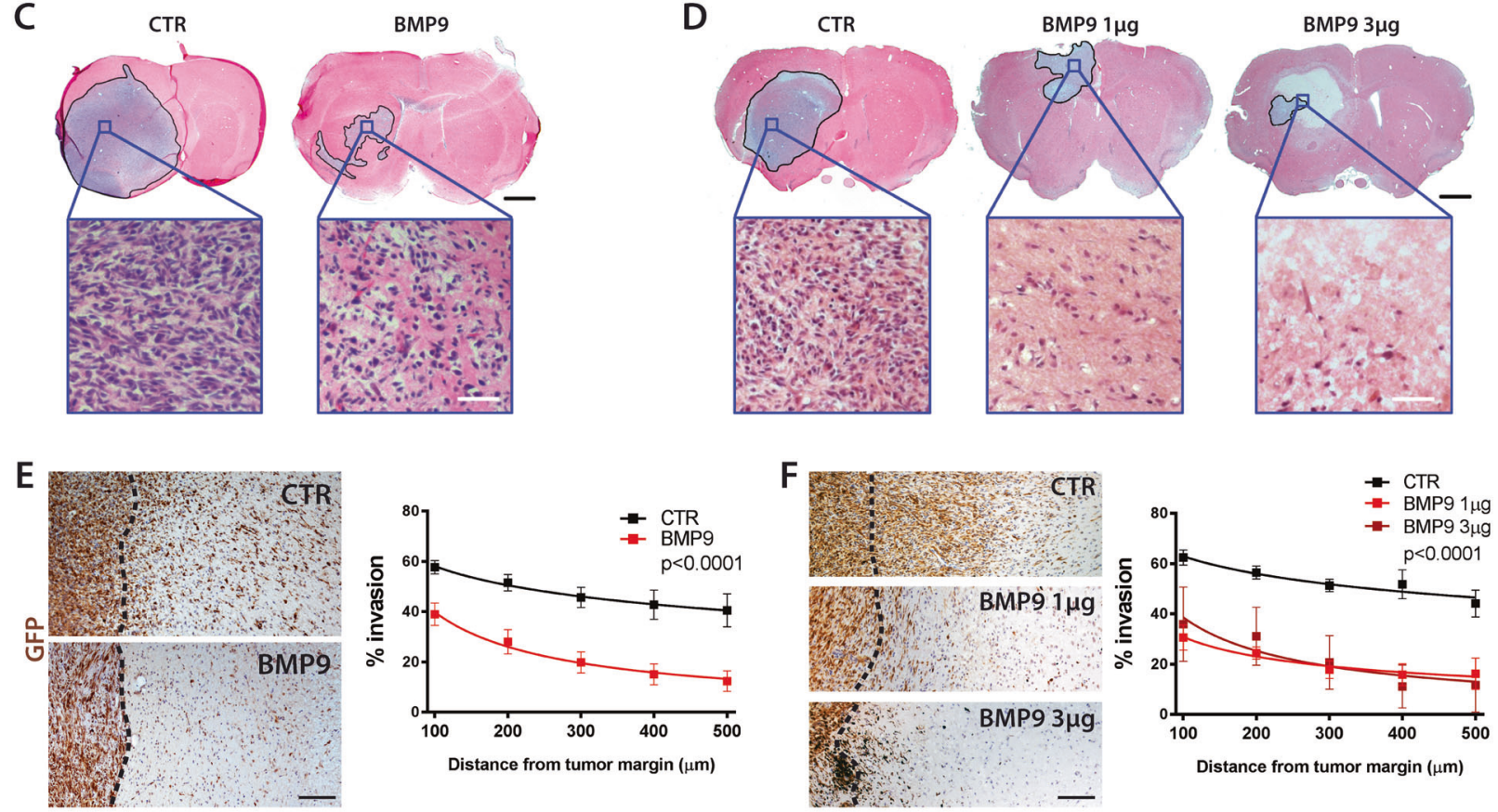

G

CTR

BMP9
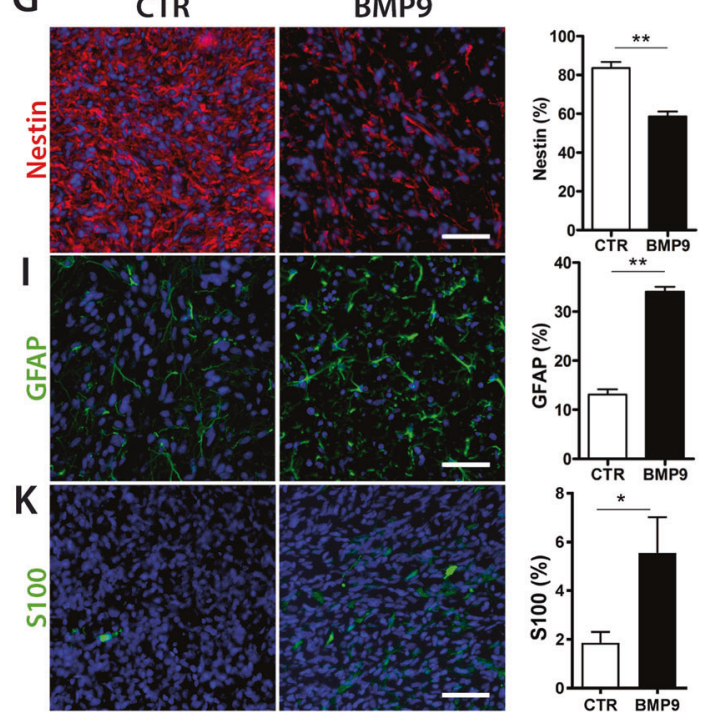

H CTR
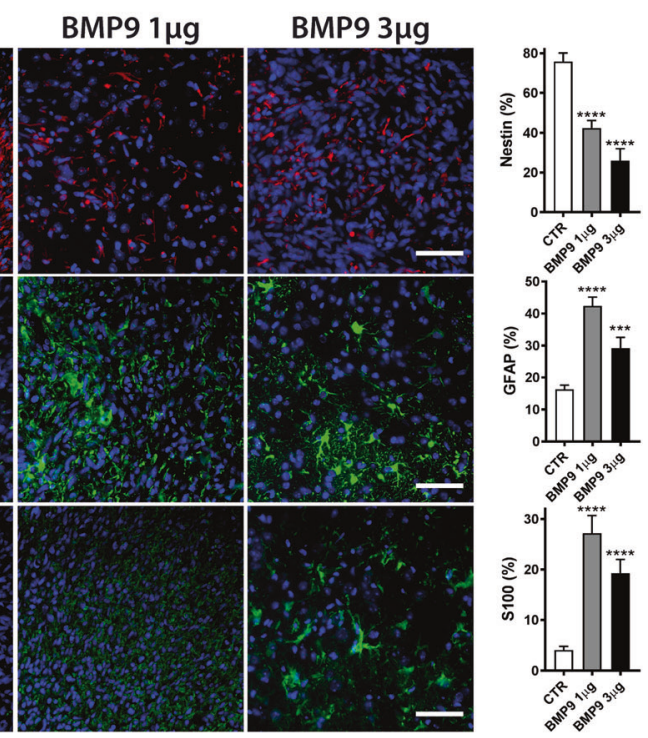

Analysis of cellular phenotype revealed that BMP9 administration through both treatment protocols induced a potent and long-lasting glial differentiation of GBM cells as shown by a strong reduction of the amount of Nestin ${ }^{+}$ cells and a concomitant increase of the $\mathrm{GFAP}^{+}$and $\mathrm{S}_{100}{ }^{+}$ subpopulations (Fig. $6 \mathrm{~g}-1$ ).

Since we previously showed that BMP9 inhibited in vitro the process of GSC transdifferentiation into TDECs (Fig. 4), 
Fig. 6 BMP9 effects on GBM growth and stemness in orthotopic murine xenografts. Tumor growth represented by bioluminescence quantification for $N=16$ control versus $N=11$ BMP9 pre-treated mice (left panel) and representative images (3 mice/experimental group) of the bioluminescence signals generated by human GBM tumors growing in NOD/SCID mice orthotopically injected with GFPLUC transduced primary cells (HuTuP83). The figure shows mice injected with cells pre-treated with BMP9 for 10 days in vitro versus control cells (right panel). (a) Bioluminescence quantification for control established tumors $(N=5)$ versus $N=6$ BMP9 $1 \mu \mathrm{g}$ and $N=6$ BMP9 $3 \mu \mathrm{g}$ treated mice with osmotic pumps (left panel). Representative images of brain bioluminescence in control tumors versus BMP9-treated mice (right panel) (b). Hematoxylin and Eosin staining of total brain sections of human GBM xenografts. The selected regions represent the tumor area (upper images, original magnification $1 \times$, scale bar $=50 \mu \mathrm{m}$ ), with insets showing a $40 \times$ magnification (lower, scale bar $=25 \mu \mathrm{m}$ ) (c and $\mathbf{d}$ for pre-treatment and post-treatment, respectively). Representative immunohistochemical images of GBM xenograft sections stained for GFP (brown) (original magnification $10 \times$, scale bar $=50 \mu \mathrm{m}$ ) and relative quantification of the $\%$ of cells invading adjacent tissues (right panels) (e and $\mathbf{f}$ for pre-treatment and post-treatment, respectively). GBM xenograft sections stained for Nestin (red, g-h), GFAP (green, i-j), S100 (green, k-l) (original magnification $20 \times$, scale bar $=50 \mu \mathrm{m}$ ) and relative quantification (right panels) (g, i, $\mathbf{k}$ and $\mathbf{h}, \mathbf{j}, \mathbf{l}$ for pre-treatment and post-treatment, respectively). Data are presented as mean \pm S.E.M. $* p<0.05$; $* * p<$ 0.01 ; $* * * p<0.001$; $* * * * p<0.001$ by paired $t$-test or One-way ANOVA

we analyzed this potential effect also in vivo. In this context, we measured the contribution of human GBM cellderived ECs to the developing murine vascular network by differentially stain vessels and GFP-expressing TDECs with anti-human CD31/anti-GFP or anti-mouse/anti-human CD31 antibody combinations (Suppl. Fig. S10A, B). BMP9 treated (pre-treated or treated with $3 \mu \mathrm{g}$ BMP9 infusion) tumors displayed a dramatic reduction (more than 50\%) of the number of TDECs, relative to control mice (Fig. 7a-c). Interestingly, also the whole angiogenic process was negatively affected by BMP9, which decreased the microvascular density (MVD; human (h) + mouse (m) $\mathrm{CD} 31^{+}$vessels) (Fig. 7d-f) and the number of $\mathrm{mCD} 31^{+}$ vessels supported by TDECs $\left(\mathrm{hCD} 31^{+}\right.$) (Fig. 7g). Finally, in order to further analyze the effects of BMP9 on the GBM-dependent angiogenic process, we investigated the vascular mimicry (VM) process, already described to occur in glioma [46]. Indeed, it has been reported that a peculiar subset of GBM cells is capable to self-organize into aberrant CD31 ${ }^{-}$vascular-like tubules, strongly enriched in extracellular matrix deposits in order to provide them structural support [47]. The double staining of xenograft slides with PAS and CD31 $(\mathrm{h}+\mathrm{m})$ suggests the existence of $\mathrm{PAS}^{+} /$ CD31 ${ }^{-}$vessels, likely derived from a VM process (Suppl. Fig. S10C). Surprisingly, BMP9 treatment was able to almost abolish these VM-derived vessels (Fig. 7h).

All these data confirm our in vitro results and suggest BMP9 as a potent modulator of GBM growth and phenotype by interfering at multiple levels with GBM cell proliferation, motility, stemness and pro-angiogenic behavior.

\section{Discussion}

Given the intrinsic resistance to common treatments displayed by GBM tumors [2], the setup of new therapeutic strategies is needed in order to obtain an efficient eradication of refractory malignant cells. Here, starting from the observation that $\mathrm{CD}_{133^{+}}$GSCs express very low levels of BMP9 and its target Endoglin relative to the remaining GBM cell population (Suppl. Fig. S11A), we evaluated the potential role of BMP9 in modulating GBM cell differentiation and aggressiveness. Although the exploration of the mechanism by which GSCs seem to be able to switch off BMP9 expression was not investigated in this study, these data fit well with the results reported here.

Both ALK1 and ALK5 receptors may accommodate the binding of BMP9, thus inducing the phosphorylation of SMAD1/5/8 and SMAD2/3 intracellular mediators [48]. BMP9 exerts a concomitant activation of both pathways in GBM cells. Nevertheless, we can not exclude that a mutual exclusive activation of these factors may occur in phenotypically diverse subpopulations. In addition, the participation of Notch signaling to the BMP9-induced transcriptional activation [33] definitely increases the intricacy of signals involved in sustaining BMP9 functions. The first effect of BMP9 that we observed in our study was a clear-cut reduction of GBM cell proliferation. A similar effect has already been reported for BMP9 in lung, gastric and breast cancers in which PI3K/AKT and MAPK pathway inhibition was suggested to play a crucial role [17, 34, 35]. Here we show that inhibition of PI3K/AKT and MAPK signalings results in the accumulation of the cell cycle inhibitors p21 and p27, molecularly corroborating our results.

One of the major cause of GBM recurrence is cancer cell dissemination [49]. BMP9 has been shown to regulate the expression of multiple extracellular matrix proteins and, particularly, to inhibit cancer cell migration and invasion through affecting matrix metalloproteinases levels in osteosarcoma and breast cancer [50, 51]. We confirmed these results in GBM by showing a defective invasive abilities of treated cells in vitro and in vivo. In our experimental setting, the mechanism underlying the BMP9mediated regulation of these functions seem to involve the RhoA-Cofilin axis which, together with MMP9 are subjected to a strong BMP9-dependent reduction of their levels. In this context, PI3K/AKT and MEK/ERK have been reported to regulate the metastatic potential of cancer cells through a positive control of MMP9 expression [52, 53], 
A

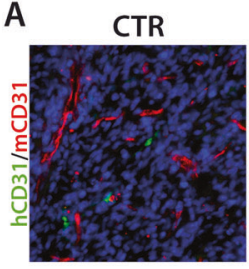

D

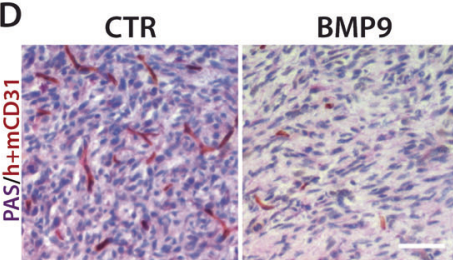

BMP9

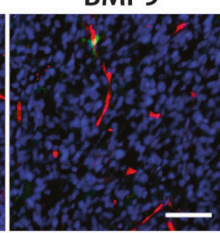

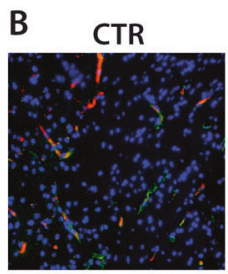

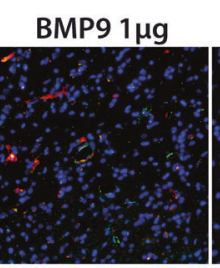

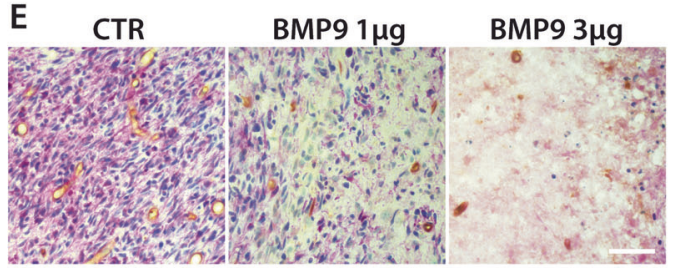

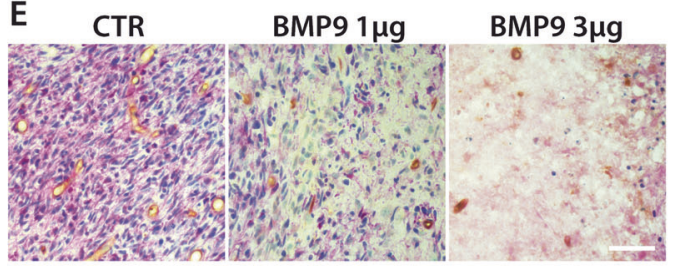

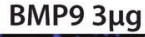
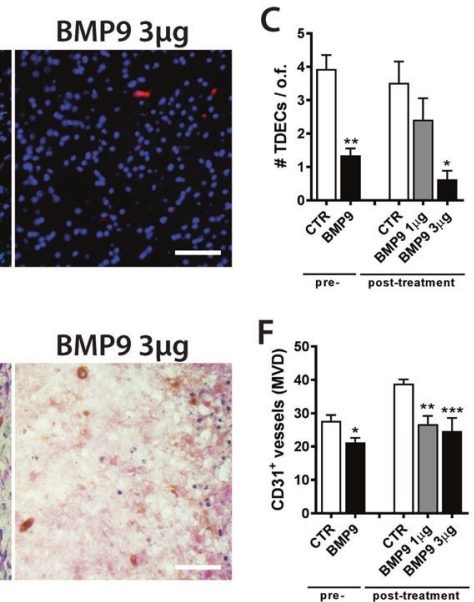
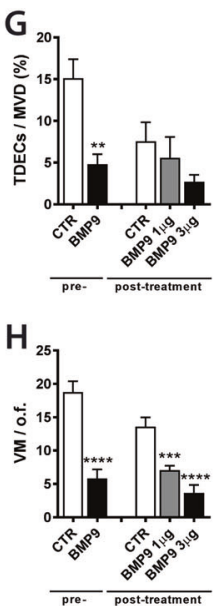

Fig. 7 BMP9 negatively affects TDEC formation and tumor angiogenesis in vivo. Representative immunofluorescence stainings of tumor sections for human CD31 (hCD31, green) and mouse CD31 $(\mathrm{mCD} 31$, red) (original magnification $20 \times$, scale bar $=50 \mu \mathrm{m})$, in pretreated (a) and post-treated (b) mice. Measurement of the number of TDECs/optical field (c). Representative immunohistochemical images of human and murine CD31 ${ }^{+}$vessels (brown) combined with PAS staining (purple) (original magnification $40 \times$, scale bar $=25 \mu \mathrm{m}$ )

thus providing a potential integrated interpretation of the multiple intracellular events sharing an upstream BMP9 modulation.

Many authors already reported a potent prodifferentiating activity triggered by BMP2 [5, 22], BMP4 [20] and BMP7 [19, 23, 24] on GSCs. In these studies, activation of BMP signaling was sufficient to dramatically inhibit the stem-like properties of primary GBM cultures both in vitro and in vivo, by inducing a multi-lineage neural differentiation. Information regarding the potential effects exerted by BMP9 on GSCs has been never reported so far. Here, we demonstrate that BMP9 retains a similar behavior as other BMPs in counteracting GBM stem cells by promoting their differentiation, not only in vitro, but also in vivo in human xenografts in mice. Intriguingly, the ability to induce a non-lineage specific differentiation was confirmed also for BMP9, although acquisition of astrocytic-like traits was predominantly observed in our context.

Hypoxic microenvironment plays a key role in sustaining GBM invasiveness [30] and undifferentiated phenotype [7] with the additional intrinsic ability of boosting neovascularization to provide cancer subsistence [31]. Hardee et al. finely described the multiple mechanisms by which neo-vascularization in gliomas occurs, finally stating that an effective inhibition of some of these processes may be a peerless challenge for the actual anti-angiogenic strategies [54]. Indeed, the described increase in vascular co-option, together with the stimulation of further pro-angiogenic factors sustained by hypoxia, may contribute to a provascular phenotype able to escape from anti-angiogenic (d and e for pre-treatment and post-treatment, respectively) and relative quantification of the microvascular density (MVD) (f). Bar graph reporting the percentage of TDECs on the total number of microvessels (g). Quantification of vascular mimicry expressed as number of $\mathrm{PAS}^{+} / \mathrm{CD} 31^{-}$microvessels/optical field (h). o.f. $=$optical field. Data are presented as mean \pm S.E.M. $* p<0.05 ; * * p<0.01 ; * * * p<0.001$; $* * * * p<0.001$ by paired $t$-test or One-way ANOVA

treatments [54]. Furthermore, a quote of GSCs may possess the ability to transdifferentiate into endothelial cells that display low/absent sensitivity to bevacizumab or other antiVEGFR therapies $[12,55,56]$, due to the proven lack of VEGFR expression [10].

Our experimental results clearly support the assignment to BMP9 of unique anti-angiogenic properties which seem not to be shared with other BMP ligands or inhibitors (Suppl. Fig. S11B). Indeed, we intriguingly found that BMP9: (i) inhibits GBM xenograft neo-vascularization in mice; (ii) slows down the phenomenon of GSC-endothelial transdifferentiation, by decreasing the expression of multiple endothelial specific markers and counteracting their functional organization into vascular structures; (iii) basically abrogates vascular mimicry, although this process seems not to be a major contributor in GBM-induced angiogenesis. Given the previously demonstrated proangiogenic activity exerted by BMP9 signaling, not only in normal ECs [48], but also in melanoma, breast carcinoma, head and neck and pancreatic cancers [57, 58], it seems quite surprising that it might act as an anti-vascular agent in GBM. Nevertheless, a BMP9-dependent decrease of VEGF expression has been already reported in ECs [59] and, in peculiar ex vivo conditions, it has been shown to inhibit EC sprouting and neo-angiogenesis [28]. Here, we observed similar effects which suggest that BMPs are likely to operate in a dose- and context-dependent way in normal and pathologic tissues. Given the complex crosstalk between different cellular entities and the coexistence of multiple deregulated signaling pathways, it is tempting to hypothesize that GBM microenvironment could play a 
fundamental role in redirecting BMP9 functions. In particular, it has already been demonstrated that a reciprocal regulation between BMP2/4 and the hypoxic mediator HIF$1 \alpha$ exists $[5,60]$, allowing to speculate that a potential hypoxic microenvironment-dependent ignition of a specific transcriptional activity may occur also for BMP9. Moreover, given the observed effects of BMP9 on GBM cell aggressiveness, phenotype and pro-angiogenic features, we can hypothesize that GBM tumors can adapt their transcriptional behavior in order to limit BMP9 expression (Suppl. Fig. S11A), thus easing their growth and dissemination.

Finally, to the best of our knowledge, we report for the first time a previously unexplored inhibitory function of BMP9 against the process of VM in GBM xenografts. This unforeseen function could be probably explained by previous studies demonstrating a BMP9 role in extracellular matrix protein deposition and remodeling [50], even if further studies would be necessary in order to identify the molecular mechanisms underlying this effect.

Our data clearly suggest that BMP9 may act as a strong inhibitor of GBM aggressiveness, by reducing cell proliferation and dissemination and inducing the decrease of cells endowed with stem-like characteristics, which intrinsically sustain therapy resistance [5]. Moreover, we describe an additional intriguing function of BMP9 as a potent inhibitor of tumor angiogenesis in GBM, thus conferring to this factor the dual potential of counteracting the prosurvival effects exerted by both the hypoxic microenvironment [7] and the peri-vascular niches [61]. For these reasons, a better comprehension of the molecular mechanisms by which BMP9 exerts its inhibitory effects, promises the future development of novel therapies based on the administration of an all-in-one agent targeting both tumor parenchyma and its pro-angiogenic microenvironment.

\section{Materials and Methods}

\section{Cell cultures and treatments}

Primary GBM cells were isolated from GBM tumors at surgery and cultured as previously described [38]. Written informed consent for the donation of adult tumor brain tissues was obtained from patients before tissue collection under the auspices of the protocol for the acquisition of human brain tissues obtained from the Ethical Committee of the Padova University-Hospital. All tissues were acquired following the tenets of the Declaration of Helsinki. Briefly, tumor biopsies were subjected to mechanical dissociation and cell suspension cultured on fibronectin coated dishes in a "GBM medium" composed of DMEM/F12 supplemented with 10\% BIT9500 (Stemcell
Technologies Inc., Vancouver, Canada), $20 \mathrm{ng} / \mathrm{ml}$ basic Fibroblast Growth Factor (bFGF; Sigma-Aldrich S.r.l., Milan, IT) and $20 \mathrm{ng} / \mathrm{ml}$ Epidermal Growth Factor (EGF; R\&D Systems, Minneapolis, MN).

Cells were not cultured for more than 8 passages in vitro in order to avoid long term culture related effects. In some experiments, $1 \times 10^{5}$ GBM cells were cultured in P6 wells in "EC medium" made up of M200 supplemented with Low Serum Growth Supplement, (Life technologies, Carlsbad, CA) for 10 days, to reproduce in vitro the transdifferentiation of GSCs into TDECs.

Both GBM cells and GBM-derived EC were maintained in an atmosphere of $2 \%$ oxygen, $5 \%$ carbon dioxide and balanced nitrogen in a Ruskinn C300 system for a proper cell expansion in hypoxic conditions (Ruskinn Technology Ltd, Bridgend, UK).

Treatment with human recombinant BMP9 (Peprotech, London, UK) was performed every other day at a final concentration of $30 \mathrm{ng} / \mathrm{ml}$. BMP9-related cytotoxicity was assayed by trypan blue exclusion and cell proliferation measured by the 3-(4,5-dimethylthiazol-2-yl)-2,5-diphenyl tetrazolium bromide (MTT) test.

For some experiments, the HuTuP13 primary GBM cells have been transduced with a GFP expressing lentiviral construct and imaging obtained by fluorescence microscopy (Exacta + Optech Labcenter Spa, San Prospero, IT). Information regarding primary GBM cultures used in this study are reported as Suppl. Table S1.

\section{Immunoblotting}

Proteins were extracted from GBM cells after 3 or $6 \mathrm{~h}$ of treatment with BMP9 $30 \mathrm{ng} / \mathrm{ml}$. Equal amounts of proteins $(10 \mu \mathrm{g})$ were resolved by SDS PAGE gels and transferred to polyvinylidene difluoride (PVDF) Immobilon-p membrane (Merk-Millipore, Darmstadt, DE). After blocking with Iblock $^{\mathrm{TM}}$ (Thermo Fisher Scientific, Waltham, MA) for at least $1 \mathrm{~h}$ at room temperature, membranes were incubated overnight at $4{ }^{\circ} \mathrm{C}$ with primary antibodies listed in Suppl. Table S2. $\beta$-actin (Sigma-Aldrich, Saint Louis, MO) was used as loading control. Membranes were next incubated with peroxidase-labeled secondary antibodies for $60 \mathrm{~min}$. All membranes were visualized using ECL Select and exposed to Hyperfilm MP (GE Healthcare, Little Chalfont, UK).

\section{Quantitative real-time PCR (qRT-PCR)}

Relative mRNA expression was measured by real-time PCR, using GUSB as reference gene. Total RNA was isolated from GBM cells treated with BMP9 for the indicated time-points using TRIzol reagent (Invitrogen, Carlsbad, CA) and then subjected to retro-transcription using 
Superscript II Reverse Transcriptase (Invitrogen, Carlsbad, CA) according to the manufacturer's instructions. qRT-PCR was performed using SYBR Green (Applied Biosystem, Foster City, CA) and analyzed on an ABI PRISM 7900HT Sequence detection system (Applied Biosystems, Foster City, CA) by the $\Delta \Delta$ ct method. Oligonucleotides used to amplify mRNA fragments are reported in Suppl. Table S3.

\section{Scratch, migration and invasion assays}

GBM cell migration was analyzed by gently "scratching" a confluent cell monolayer (treated or not with BMP9 $30 \mathrm{ng}$ / $\mathrm{ml}$ ) and then measuring the ability of borderline cells to move into and close the scratch during time (from 6 to $72 \mathrm{~h}$ ). Images were acquired by using a Nikon SMZ1500 microscope (Nikon, Melville, NY) and wound width measured in at least four random fields by using Adobe Photoshop CS6 (Adobe Systems Incorporated, La Jolla, CA; www.adobe.com).

Cell migration was further monitored by seeding cells onto $8 \mu \mathrm{m}$ transwells and by analyzing the migrated cells in the underlying compartment after $24 \mathrm{~h}$. Cells were stained with $0.5 \%$ Crystal violet in $20 \%$ methanol. Images were captured with a Nikon TS100 inverted microscope (Nikon, Melville, NY). Crystal violet was further solubilized with $0.2 \%$ SDS solution in $15 \%$ ethanol for $30^{\prime}$ at $37^{\circ} \mathrm{C}$, and then measured at $560 \mathrm{~nm}$ using a VICTOR3 spectrophotometer (Perkin Elmer, Milan, IT).

GBM invasion was evaluated using the $\mathrm{CultreCoat}^{\circledR} 24$ Well BME Cell Invasion Assay (Trevigen, Gaithersburg, MD) according to the manufacturer's instructions. Invasion was measured $48 \mathrm{~h}$ after plating, at $485-520 \mathrm{~nm}$ using a VICTOR3 spectrophotometer (Perkin Elmer, Milan, IT).

\section{Neurosphere forming and limiting dilution assays}

For the neurosphere forming assay, GBM cells pre-treated with BMP9 for 10 days and relative control cells were counted and plated as single cells on tissue culture plates at a density of $1 \times 10^{3}$ cells per P6 well in non adherent conditions. The number of generated neurospheres was recorded after 21 days of culture (cell replating \#1) (medium refresh once a week). Images were captured with Nikon SMZ1500 microscope (Nikon, Melville, NY), and the area of neurospheres measured by ImageJ software (https://ima gej.nih.gov). Cells were further isolated, seeded and monitored for additional 21 days (cell replating \#2). The number of neurospheres was measured also at this time-point.

To assess the GBM initiating cell frequency we seeded cells pre-treated with BMP9 for 10 days and relative control cells at pre-determined cell dilutions in P96 wells. The proportion of wells containing no spheres was recorder after at least two additional weeks of culture and the frequency of GBM cells endowed with initiating properties calculated.

\section{Flow cytometry and immunofluorescence of cultured cells}

For flow cytometry analysis, GBM cells were treated with BMP9 for 10 days, detached and then stained with primary antibodies as listed in Suppl. Table S2. For unconjugated antibodies, cells were then incubated with the appropriate species specific secondary antibodies conjugated with Alexa dyes (1:500, Molecular Probes, Carlsbad, CA). Samples were analyzed on a Cytomic FC500 or Cytoflex flow cytometer (Beckman Coulter, Brea, CA). Data are presented as percentage of positive-cells in the live-gated cell subpopulation.

For immunofluorescence imaging, cells were fixed in cold $4 \%$ formaldehyde for $15 \mathrm{~min}$, rinsed and stained with phalloidin-FITC $(50 \mu \mathrm{g} / \mathrm{ml}$, Sigma-Aldrich S.r.l., Milan, IT), or in alternative with primary antibodies as reported in Suppl. Table S2. After incubation, cells were washed and labeled with species specific secondary antibodies conjugated with Alexa dyes (1:1000, Molecular Probes, Carlsbad, CA). Cells were counterstained with DAPI ( $1 \mu \mathrm{g} /$ $\mathrm{ml}$, Sigma-Aldrich, St. Louis, MO). Finally, images were obtained by using an Eclipse Ti80 video-confocal microscope (Vico, Nikon, Melville, NY) or a Zeiss Axio Imager M1 epifluorescence microscope (Zeiss, Oberkochen, Germany)

\section{Capillary tube formation assay}

$3 \times 10^{4}$ GBM cells were pre-treated for 10 days with BMP9 every other day at $30 \mathrm{ng} / \mathrm{ml}$ and then seeded over Matrigel matrix (Basement membrane matrix, BD Biosciences, Franklin Lakes, NJ) to allow the capillary tubes to form within $24 \mathrm{~h}$, as previously described [39]. Images were acquired with a Nikon SMZ1500 microscope (Nikon, Melville, NY) and then analyzed by using ImageJ software (Angiogenesis plug-in; https://imagej.nih.gov) and accounting for the number of meshes and branches of the capillary structures, as described [38]. Values were expressed as relative deviations (\%) from control cultures grown in GBM medium.

\section{Generation of human orthotopic GBM xenograft model in mice}

Animal experiments were approved by our local animal ethics committee and were executed in accordance with national guidelines and regulations. Procedures involving animals and their care were conformed with institutional guidelines that comply with national and international laws 
and policies (EEC Council Directive 86/609, OJ L 358, 12 December 1987) and with "ARRIVE" guidelines (Animals in Research Reporting In Vivo Experiments); Ministry authorization number: 411/2015-PR.

GBM cells (HutuP83 or HuTuP13, $3 \times 10^{5}$ cells/mouse) were transduced with a bicistronic construct pCCL.sin. cPPT.SV40polyA.eGFP.minCMV.hPGK.deltaLNGFR.

Wpre in which deltaLNGFR has been substituted with firefly luciferase coding sequence, and orthotopically injected into the brain of 8-10-week-old female NOD/SCID mice (coordinates used were anterior/posterior: $-0.5 \mathrm{~mm}$, medial/lateral: $-1.5 \mathrm{~mm}$ from bregma and dorsal/ventral: $2.5 \mathrm{~mm}$ ). Treatment with BMP9 was performed with two different strategies: (i) GFP-LUC-transduced GBM cells pre-treated in vitro for 10 days with BMP9 $30 \mathrm{ng} / \mathrm{ml}$ were stereotaxically injected into the mice brain; (ii) established GBM xenografts were treated with two dosages of BMP9 ( 1 or $3 \mu \mathrm{g} / 14$ days) by adopting intracranial osmotic pumps (ALZET pumps \#2002 and ALZET Brain Infusion Kit 3, Charles River Laboratories, Milano, IT), according to the manufacturer's instructions, and as reported in the Suppl. Fig. S9A.

In vivo imaging of growing xenografts was performed at pre-determined time-points by intraperitoneally injecting $10 \mu \mathrm{l} / \mathrm{g}$ body weight of XenoLight D-luciferin firefly $(15 \mathrm{mg} / \mathrm{ml}$ in PBS; Perkin Elmer, Waltham, MA), and detecting brain luminescence with a Xenogen IVIS Lumina II System (Xenogen Corporation, Alameda, CA). Data analysis was performed using Living Image software, and the intensity of the signal was quantified in the regions of interest. Radiance unit was expressed as number of photons (p) per second (s) that leave a square centimeter of tissue $\left(\mathrm{cm}^{2}\right)$ and radiate into a solid angle of one steradian ( $\left.\mathrm{sr}\right), \mathrm{p} / \mathrm{s} /$ $\mathrm{cm}^{2} / \mathrm{sr}$ ).

Once tumors had grown until pre-determined time points, and before the appearance of any neurological defect, mice were intracardially perfused with PFA 4\% PBS $1 \times$, at a constant flow rate $(3 \mathrm{ml} / \mathrm{min})$, and then brains extracted and cryoprotected in sucrose. GBM bearing mice brains were included in OCT compound and stored at $-130{ }^{\circ} \mathrm{C}$ until being cryosectioned for histology, immunohistochemistry and immunofluorescence analyses.

\section{Hystology, immunohistochemistry, and immunofluorescence of brain sections}

For immunohistochemistry, $10 \mu \mathrm{m}$ sections were re-hydrated, blocked with $1.5 \%$ pre-immune serum and then stained with specific primary antibodies as listed in Suppl. Table S2. Slides were subsequently washed and incubated with the appropriate secondary antibodies. Immunostaining was performed using the avidin-biotin-peroxidase complex technique (Vectastain ABC kit; Vector Labs, Burlingame,
CA), and 3,3'-diaminobenzidine (DAB kit; Dako, Glostrup, DK) was used as a chromogen substrate. Finally, tumor sections were counterstained with Mayer's haematoxylin (Sigma-Aldrich, Saint Luis, MO). For some analyses, both anti-human and anti-mouse CD31 primary antibodies were concomitantly used to visualize the entire tumor vasculature (both TDECs and mouse EC-derived vessels) and combined with a standard PAS staining.

The MVD was assessed by counting the number of vessels in 5 fields per section, using a $40 \times$ objective. Images were collected with a Zeiss Axio Imager M1 microscopy (Zeiss, Oberkochen, DE).

Immunofluorescence was performed with standard procedures. Briefly, slides were re-hydrated, blocked and then stained with primary antibodies as listed in Suppl. Table S2. Appropriate Alexa conjugated secondary antibodies were used (1:1000, Life technologies, Carlsbad, CA). Finally, samples have been counterstained with DAPI $(1 \mu \mathrm{g} / \mathrm{ml}$, Sigma-Aldrich, Saint Luis, MO). Images were collected with a Nikon Eclipse Ti80 video-confocal microscopy (ViCo, Nikon, Melville, NY) or a Zeiss Axio Imager M1 epifluorescence microscope (Zeiss, Oberkochen, Germany).

Hematoxylin and eosin staining has been performed with standard techniques. Whole brain images were captured with a Nikon SMZ100 microscope (Nikon, Melville, NY) at $1 \times$ magnification.

\section{Statistical analyses}

Graphs and associated statistical analyses were generated using Graph Pad Prism 7.03 (GraphPad, La Jolla, CA). In general, data have been generated by performing the experiments in at least two different primary cell cultures and repeating them at least three times in each cell culture. Unless differently indicated, all data are presented as mean \pm standard error of the mean (S.E.M.). Statistical significance was measured by $t$-test (comparison of two groups) or Oneway ANOVA (comparison of three or more groups) with Newman-Keuls multiple comparison post test. Statistical differences among the different wound closure or GBM xenograft growth curves reported in the manuscript were calculated by interpolating non-linear regressions of each dataset and comparing them by Extra sum-of-squares $F$ test. ${ }^{*} p<0.05 ; * * p<0.01 ; * * * p<0.001 ; * * * * p<0.0001$.

Additional materials and methods are provided as Supporting information.

Acknowledgements We are grateful to Dr. Luisa Galla, Dr. Claudia Lodovichi (Venetian Institute of Molecular Medicine-VIMM, Padova, Italy., National Research Council-CNR, Neuroscience Institute, Milan, Italy) and Dr. Ludovico Scenna (designed Veterinarian, University of Padova) for technical help in stereotaxic surgery and mice perfusion techniques. Moreover, we thank the Laboratory of Immunopathology and Molecular Biology of The Kidney, Department 
of Woman and Children Health, University of Padova, for invaluable assistance in histological procedures. This work was supported by funds from Cassa di Risparmio di Padova e Rovigo (CARIPARO) Foundation (Project no. IRP13/05) (to GB), Istituto di Ricerca Pediatrica Città della Speranza (Project n. IRP18/06) (to LP) and the Italian Association for Cancer Research (AIRC, IG-17035 and Special Program Molecular Clinical Oncology 5 per mille ID 10016) (to AR). EP was supported by a fellowship from AIRC (n.14978 and n.16601) and from Umberto Veronesi Foundation (FUV, n.1142). FM is supported by a fellowship from AIRC (n.19575).

Author contributions: Conceived and designed the experiments: EP, LP. Performed the experiments: EP, FM, DB, ER, VB, CF, GZ. Analyzed the data: EP, LP, GZ, GV. Contributed reagents/materials/ analysis tools: ADP, AR, GB. Wrote/revised the paper: LP, EP, GB, AR, GV.

\section{Compliance with ethical standards}

Conflict of interest The authors declare that they have no conflict of interest.

\section{References}

1. Blumenthal DT, Gorlia T, Gilbert MR, Kim MM, Burt Nabors L, Mason WP, et al. Is more better? The impact of extended adjuvant temozolomide in newly diagnosed glioblastoma: a secondary analysis of EORTC and NRG Oncology/RTOG. Neuro Oncol. 2017;19:1119-26.

2. Qazi MA, Vora P, Venugopal C, Sidhu SS, Moffat J, Swanton C, et al. Intratumoral heterogeneity: pathways to treatment resistance and relapse in human glioblastoma. Ann Oncol J Eur Soc Med Oncol. 2017;28:1448-56.

3. Beier D, Schulz JB, Beier CP. Chemoresistance of glioblastoma cancer stem cells-much more complex than expected. Mol Cancer. 2011;10:128.

4. Li H, Liu Y, Jiao Y, Guo A, Xu X, Qu X, et al. Resveratrol sensitizes glioblastoma-initiating cells to temozolomide by inducing cell apoptosis and promoting differentiation. Oncol Rep. 2015;35:343-51.

5. Persano L, Pistollato F, Rampazzo E, Della Puppa A, Abbadi S, Frasson C, et al. BMP2 sensitizes glioblastoma stem-like cells to Temozolomide by affecting HIF-1 $\alpha$ stability and MGMT expression. Cell Death Dis. 2012;3:e412.

6. Persano L, Rampazzo E, Basso G, Viola G. Glioblastoma cancer stem cells: role of the microenvironment and therapeutic targeting. Biochem Pharmacol. 2013;85:612-22.

7. Pistollato F, Chen H-L, Rood BR, Zhang H-Z, D'Avella D, Denaro L, et al. Hypoxia and HIF1alpha repress the differentiative effects of BMPs in high-grade glioma. Stem Cells. 2009;27:7-17.

8. Dachs GU, Chaplin DJ. Microenvironmental control of gene expression: implications for tumor angiogenesis, progression, and metastasis. Semin Radiat Oncol. 1998;8:208-16.

9. Ricci-Vitiani L, Pallini R, Biffoni M, Todaro M, Invernici G, Cenci $\mathrm{T}$, et al. Tumour vascularization via endothelial differentiation of glioblastoma stem-like cells. Nature. 2010;468:824-8.

10. Soda Y, Marumoto T, Friedmann-Morvinski D, Soda M, Liu F, Michiue $\mathrm{H}$, et al. Transdifferentiation of glioblastoma cells into vascular endothelial cells. Proc Natl Acad Sci USA. 2011; 108:4274-80.

11. Yan H, Romero-López M, Benitez LI, Di K, Frieboes HB, Hughes $\mathrm{CCW}$, et al. 3D mathematical modeling of glioblastoma suggests that transdifferentiated vascular endothelial cells mediate resistance to current standard-of-care therapy. Cancer Res. 2017;77:4171-84.

12. Chinot OL, Wick W, Mason W, Henriksson R, Saran F, Nishikawa $\mathrm{R}$, et al. Bevacizumab plus radiotherapy-temozolomide for newly diagnosed glioblastoma. N Engl J Med. 2014;370:709-22.

13. Hegarty SV, O'Keeffe GW, Sullivan AM. BMP-Smad 1/5/8 signalling in the development of the nervous system. Prog Neurobiol. 2013;109:28-41.

14. Lavery K, Swain P, Falb D, Alaoui-Ismaili MH. BMP-2/4 and BMP-6/7 differentially utilize cell surface receptors to induce osteoblastic differentiation of human bone marrow-derived mesenchymal stem cells. J Biol Chem. 2008;283:20948-58.

15. Thawani JP, Wang AC, Than KD, Lin C-Y, La Marca F, Park P. Bone morphogenetic proteins and cancer. Neurosurgery. 2010;66:233-46.

16. Wang K, Feng H, Ren W, Sun X, Luo J, Tang M, et al. BMP9 inhibits the proliferation and invasiveness of breast cancer cells MDA-MB-231. J Cancer Res Clin Oncol. 2011;137:1687-96.

17. Wang J, Weng Y, Zhang M, Li Y, Fan M, Guo Y, et al. BMP9 inhibits the growth and migration of lung adenocarcinoma A549 cells in a bone marrow stromal cell-derived microenvironment through the MAPK/ERK and NF- $\mathrm{BB}$ pathways. Oncol Rep. 2016;36:410-8.

18. Bach D-H, Park HJ, Lee SK. The dual role of bone morphogenetic proteins in cancer. Mol Ther Oncolytics. 2018;8:1-13.

19. Tate CM, Pallini R, Ricci-Vitiani L, Dowless M, Shiyanova T, D'Alessandris GQ, et al. A BMP7 variant inhibits the tumorigenic potential of glioblastoma stem-like cells. Cell Death Differ. 2012;19:1644-54.

20. Piccirillo SGM, Reynolds Ba, Zanetti N, Lamorte G, Binda E, Broggi $G$, et al. Bone morphogenetic proteins inhibit the tumorigenic potential of human brain tumour-initiating cells. Nature. 2006;444:761-5.

21. Nakano I, Saigusa K, Kornblum HI. BMPing off glioma stem cells. Cancer Cell. 2008;13:3-4.

22. Rampazzo E,Dettin M,Maule F,Scabello A,Calvanese L,D'Auria $\mathrm{G}$, et al. A synthetic BMP-2 mimicking peptide induces glioblastoma stem cell differentiation. Biochim Biophys Acta Gen Subj. 2017;1861:2282-92.

23. Reguera-Nuñez E, Roca C, Hardy E, de la Fuente M, Csaba N, Garcia-Fuentes M. Implantable controlled release devices for BMP-7 delivery and suppression of glioblastoma initiating cells. Biomaterials. 2014;35:2859-67.

24. Tso JL, Yang S, Menjivar JC, Yamada K, Zhang Y, Hong I, et al. Bone morphogenetic protein 7 sensitizes O6-methylguanine methyltransferase expressing-glioblastoma stem cells to clinically relevant dose of temozolomide. Mol Cancer. 2015;14:189.

25. Bai H, Gao Y, Arzigian M, Wojchowski DM, Wu W-S, Wang ZZ. BMP4 regulates vascular progenitor development in human embryonic stem cells through a Smad-dependent pathway. J Cell Biochem. 2010;109:363-74.

26. Wooderchak-Donahue WL, McDonald J, O'Fallon B, Upton PD, $\mathrm{Li}$ W, Roman BL, et al. BMP9 mutations cause a vascularanomaly syndrome with phenotypic overlap with hereditary hemorrhagic telangiectasia. Am J Hum Genet. 2013;93:530-7.

27. van Meeteren La, Thorikay M, Bergqvist S, Pardali E, Stampino $\mathrm{CG}$, Hu-Lowe D, et al. Anti-human activin receptor-like kinase 1 (ALK1) antibody attenuates bone morphogenetic protein 9 (BMP9)-induced ALK1 signaling and interferes with endothelial cell sprouting. J Biol Chem. 2012;287:18551-61.

28. Scharpfenecker M, van Dinther M, Liu Z, van Bezooijen RL, Zhao Q, Pukac L, et al. BMP-9 signals via ALK1 and inhibits bFGF-induced endothelial cell proliferation and VEGF-stimulated angiogenesis. J Cell Sci. 2007;120:964-72. 
29. Lamplot JD, Qin J, Nan G, Wang J, Liu X, Yin L, et al. BMP9 signaling in stem cell differentiation and osteogenesis. Am J Stem Cells. 2013;2:1-21.

30. Oliver L, Olivier C, Marhuenda FB, Campone M, Vallette FM. Hypoxia and the malignant glioma microenvironment: regulation and implications for therapy. Curr Mol Pharmacol. 2009;2:263-84.

31. Pugh CW, Ratcliffe PJ. Regulation of angiogenesis by hypoxia: role of the HIF system. Nat Med. 2003;9:677-84.

32. Caja L, Bellomo C, Moustakas A. Transforming growth factor $\beta$ and bone morphogenetic protein actions in brain tumors. FEBS Lett. 2015;589:1588-97.

33. Borggrefe T, Lauth M, Zwijsen A, Huylebroeck D, Oswald F, Giaimo BD. The Notch intracellular domain integrates signals from Wnt, Hedgehog, TGF $\beta /$ BMP and hypoxia pathways. Biochim Biophys Acta Mol Cell Res. 2016;1863:303-13.

34. Duan L, Ye L, Wu R, Wang H, Li X, Li H, et al. Inactivation of the phosphatidylinositol 3-kinase/Akt pathway is involved in BMP9-mediated tumor-suppressive effects in gastric cancer cells. J Cell Biochem. 2015;116:1080-9.

35. Ren W, Liu Y, Wan S, Fei C, Wang W, Chen Y, et al. BMP9 inhibits proliferation and metastasis of HER2-positive SK-BR-3 breast cancer cells through ERK1/2 and PI3K/AKT pathways. PLoS ONE. 2014;9:e96816.

36. Thornton TM, Rincon M. Non-classical p38 map kinase functions: cell cycle checkpoints and survival. Int J Biol Sci. 2009;5:44-51.

37. Ren W, Sun X, Wang K, Feng H, Liu Y, Fei C, et al. BMP9 inhibits the bone metastasis of breast cancer cells by downregulating $\mathrm{CCN} 2$ (connective tissue growth factor, CTGF) expression. Mol Biol Rep. 2014;41:1373-83.

38. Maule F, Bresolin S, Rampazzo E, Boso D, Della Puppa A, Esposito G, et al. Annexin 2A sustains glioblastoma cell dissemination and proliferation. Oncotarget. 2016;7:54632-49.

39. Porcù E, Persano L, Ronca R, Mitola S, Bortolozzi R, Romagnoli $\mathrm{R}$, et al. The novel antitubulin agent TR-764 strongly reduces tumor vasculature and inhibits HIF-1 $\alpha$ activation. Sci Rep. 2016;6:27886.

40. Kondraganti S, Mohanam S, Chintala SK, Kin Y, Jasti SL, Nirmala C, et al. Selective suppression of matrix metalloproteinase-9 in human glioblastoma cells by antisense gene transfer impairs glioblastoma cell invasion. Cancer Res. 2000;60:6851-5.

41. Santos R, Vadodaria KC, Jaeger BN, Mei A, LefcochilosFogelquist S, Mendes APD, et al. Differentiation of inflammationresponsive astrocytes from glial progenitors generated from human induced pluripotent stem cells. Stem Cell Rep. 2017;8:1757-69.

42. Howard BM, Zhicheng Mo, Filipovic R, Moore AR, Antic SD, Zecevic N. Radial glia cells in the developing human brain. Neurosci. 2008;14:459-73.

43. Behnan J, Stangeland B, Hosainey SAM, Joel M, Olsen TK, Micci F, et al. Differential propagation of stroma and cancer stem cells dictates tumorigenesis and multipotency. Oncogene. 2017;36:570-84.

44. Zhao Y, Dong J, Huang Q, Lou M, Wang A, Lan Q. Endothelial cell transdifferentiation of human glioma stem progenitor cells in vitro. Brain Res Bull. 2010;82:308-12.

45. Wang R, Chadalavada K, Wilshire J, Kowalik U, Hovinga KE, Geber A, et al. Glioblastoma stem-like cells give rise to tumour endothelium. Nature. 2010;468:829-33.
46. El Hallani S, Boisselier B, Peglion F, Rousseau A, Colin C, Idbaih $\mathrm{A}$, et al. A new alternative mechanism in glioblastoma vascularization: tubular vasculogenic mimicry. Brain. 2010;133:973-82.

47. Mao JM, Liu J, Guo G, Mao XG, Li CX. Glioblastoma vasculogenic mimicry: signaling pathways progression and potential anti-angiogenesis targets. Biomark Res. 2015;3:8.

48. David L, Mallet C, Mazerbourg S, Feige J-J, Bailly S. Identification of BMP9 and BMP10 as functional activators of the orphan activin receptor-like kinase 1 (ALK1) in endothelial cells. Blood. 2007;109:1953-61.

49. Giese A, Bjerkvig R, Berens ME, Westphal M. Cost of migration: invasion of malignant gliomas and implications for treatment. J Clin Oncol. 2003;21:1624-36.

50. Wang W, Weng Y, Ren W, Zhang Z, Wang T, Wang J, et al. Biological roles of human bone morphogenetic protein 9 in the bone microenvironment of human breast cancer MDA-MB-231 cells. Am J Transl Res. 2015;7:1660-74.

51. Lv Z, Yang D, Li J, Hu M, Luo M, Zhan X, et al. Bone morphogenetic protein 9 overexpression reduces osteosarcoma cell migration and invasion. Mol Cells. 2013;36:119-26.

52. Chen C-M, Hsieh S-C, Lin C-L, Lin Y-S, Tsai J-P, Hsieh Y-H. Alpha-mangostin suppresses the metastasis of human renal carcinoma cells by targeting MEK/ERK expression and MMP-9 transcription activity. Cell Physiol Biochem. 2017;44:1460-70.

53. Chen J-S, Wang Q, Fu X-H, Huang X-H, Chen X-L, Cao L-Q, et al. Involvement of PI3K/PTEN/AKT/mTOR pathway in invasion and metastasis in hepatocellular carcinoma: association with MMP-9. Hepatol Res. 2009;39:177-86.

54. Hardee ME, Zagzag D. Mechanisms of glioma-associated neovascularization. Am J Pathol. 2012;181:1126-41.

55. Tamura R, Tanaka T, Miyake K, Yoshida K, Sasaki H. Bevacizumab for malignant gliomas: current indications, mechanisms of action and resistance, and markers of response. Brain Tumor Pathol. 2017;34:62-77.

56. Guelfi S, Duffau H, Bauchet L, Rothhut B, Hugnot J-P. vascular transdifferentiation in the CNS: a focus on neural and glioblastoma stem-like cells. Stem Cells Int. 2016;2016:1-13.

57. Cunha SI, Pardali E, Thorikay M, Anderberg C, Hawinkels L, Goumans M-J, et al. Genetic and pharmacological targeting of activin receptor-like kinase 1 impairs tumor growth and angiogenesis. J Exp Med. 2010;207:85-100.

58. Hawinkels LJAC,de Vinuesa AG,Paauwe M,Kruithof-deJulio M, Wiercinska E,Pardali E, et al. Activin Receptor-like Kinase 1 ligand trap reduces microvascular density and improves chemotherapy efficiency to various solid tumors. Clin Cancer Res. 2016;22:96-106.

59. Shao ES, Lin L, Yao Y, Boström KI. Expression of vascular endothelial growth factor is coordinately regulated by the activinlike kinase receptors 1 and 5 in endothelial cells. Blood. 2009;114:2197-206.

60. Wang J, Fu X, Yang K, Jiang Q, Chen Y, Jia J, et al. Hypoxia inducible factor-1-dependent up-regulation of BMP4 mediates hypoxia-induced increase of TRPC expression in PASMCs. Cardiovasc Res. 2015;107:108-18.

61. Calabrese C, Poppleton H, Kocak M, Hogg TL, Fuller C, Hamner $\mathrm{B}$, et al. A perivascular niche for brain tumor stem cells. Cancer Cell. 2007;11:69-82. 